\title{
DYNAMIC RESPONSE OF PRETENSIONED PRESTRESSED CONCRETE BEAMS
}

\author{
By \\ WAYNE A. HAMILTON \\ Bachelor of Science \\ Ohio Northern University \\ Ada, Ohio \\ 1958 \\ Master of Science \\ Case Institute of Technology \\ Cleveland, Ohio \\ 1960
}

Submitted to the faculty of the Graduate College of the Ok lahoma State University in partial fulfillment of the requirements for the degree of DOCTOR OF PHILOSOPHY Ju1y, 1967 


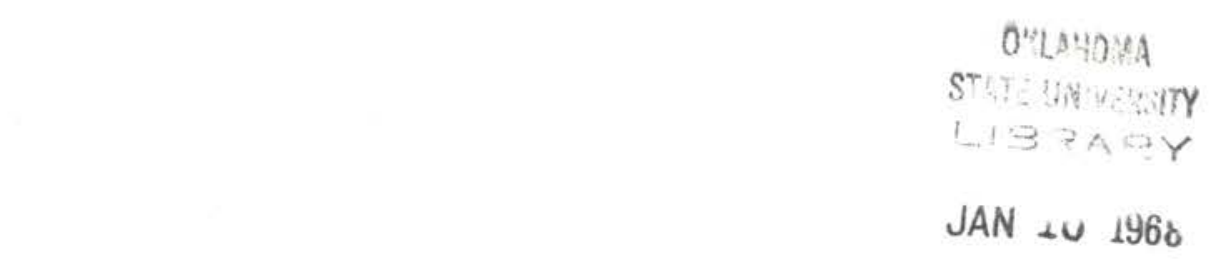

DYNAMIC RESPONSE OF PRETENSIONED

PRESTRESSED CONCRETE BEAMS

Thesis Approved:

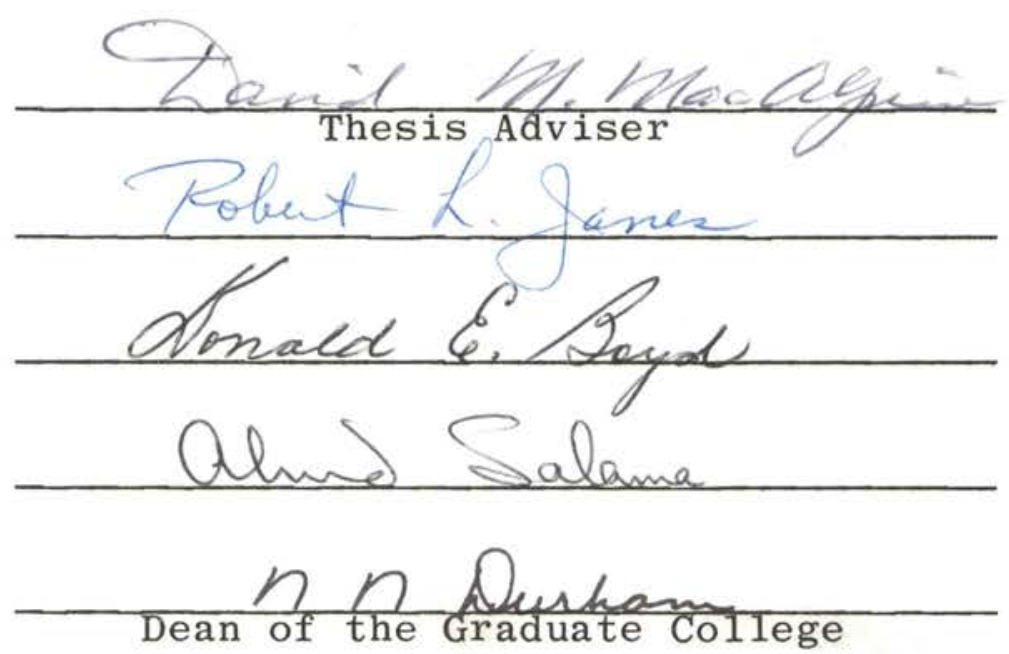

658799 


\section{ACKNOWLEDGEMENTS}

The writer wishes to express his indebtedness and sincere appreciation to the following individuals and organizations:

To Professor David M. MacAlpine, for his guidance and encouragement during the preparation of this thesis. To Professors R. L. Janes, D, E. Boyd, A. E. Salama, and Wm. L. Hughes members of the advisory committee for their helpful advice during the writer's graduate program.

To the National Science Foundation whose Faculty Fellowship made it possible for the writer to participate in the graduate study program.

To the University of Maine for providing the time to complete the program, and to their Coe Research Fund which provided funds and equipment to conduct the research 。

To Structural Concrete Corporation, Laconia, New Hampshire for providing the test members. To his wife, Kathryn, for her patience and help in editing the manuscript.

To Mrs。 Rita Hill for typing the manuscript. July, 1967 


\section{TABLE OF CONTENTS}

Chapter

Page

I . INTRODUCTION . . . . . . . . . . . . . . . . . . 1

1.1 Genera 1 . . . . . . . . . . . . . . . 1

1.2 Statement of the Problem. . . . . . 1

1.3 Historical Review . . . . . . . . 2

II. EXPERIMENTAL WORK . . . . . . . . . . . . . . 7

2.1 Dynamic Testing Machine . . . . . . 7

2.2 Instrumentation . . . . . . . . . . 9

2.3 Load and Reaction Rings . . . . . . . 12

2.4 Description and Construction of Test

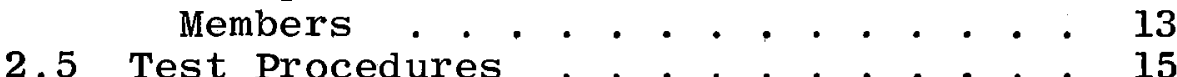

I II . THEORY . . . . . . . . . . . . . . . . . . . . . 23

3.1 Static Load-Deflection Curve . . . . 23

3.2 Dynamic Deflection-Time Curve . . . . 30

IV. RESULTS AND DISCUSSION . . . . . . . . . . . . . 34

4.1 Static Tests ........... . 34

4.2 Dynamic Tests . . . . . . . . . 35

V. FINDINGS AND CONCLUSIONS . . . . . . . . . . . 41

5.1 Summary and Conclusions . . . . . . . 41

5.2 Extension of Work . . . . . . . . . 43

SELECTED BIBLIOGRAPHY . . . . . . . . . . . . . . . . . 44

APPENDICES . . . . . . . . . . . . . . . . 47 4

A. WIRING DIAGRAMS OF INSTRUMENTATION . . . . . . . 47

B. PHOTOS OF TEST SETUP . . . . . . . . . . . . . 53

C . PHOTOS OF TEST MEMBERS . . . . . . . . . . . . 56

D. STATIC TEST RESPONSE CURVES . . . . . . . . . . 61

Application of Theory for Static Loads • . 64 
E. DYNAMIC TEST RESPONSE CURVES . . . . . . . . . . 72

Application of Theory for Dynamic Loads . . 81 


\section{LIST OF TABLES}

$\begin{array}{ll}\text { Table Page } & \text { Pag }\end{array}$

I. Ultimate Compressive Strength of Concrete . . 15

II. Summary of Dynamic Tests . . . . . . . . . . . 35

III. Theoretical and Actual Static Moments . . . . . 38

IV. Ratio of Applied Dynamic Moment to Theoretical

Static Moment . . . . . . . . . . . . . 39 


\section{LIST OF FIGURES}

Figure

Page

1. Schematic Diagram of the Dynamic Testing Machine . . . . . . . . . . . . 8

2. Stress-Strain Diagram for Prestress Stee1. . . 16

3. Pretensioned Concrete Beam Dimensions Including Instrumentation Locations . . . . . . . . . 17

4. Idealized Stress-Strain Diagram for Concrete . 24

5. Internal Forces and Strains of Beam CrossSection . . . . . . . . . . . . . 26

6. Idealized Stress-Strain Diagrams for Prestress Steel................... . 27

7. Unit Rotation Diagram at Ultimate Load . . . 31

A-1. Circuit for Displacement Transducer . . . . . . 48

A-2. Circuit for Bridge of Gages on Member . . . . . 49

A-3. Circuit for Load Ring . . . . . . . . . . . 50

A-4. Circuit for Reaction Ring . . . . . . . . . . 51

A-5. Plan View of Camera Instrumentation . . . . . . 52

B-1. Dynamic Testing Machine . . . . . . . . . . 54

B-2. Recorders . . . . . . . . . . . . . . 54

B-3. Camera Instrumentation . . . . . . . . . . 55

C-1. Photo Beam D-1 After Dynamic Load of 22.9 Kips. 57

C-2. Photo Beam D-2 After Dynamic Load of 32.5 Kips. 57

C-3. Photo Beam D-3 After Dynamic Load of 33.1 Kips. 58

C-4. Photo Beam D-4 After Dynamic Load of 29.9 Kips. 59

C-5. Photo Beam D-5 After Dynamic Load of $31.2 \mathrm{Kips} .59$ 
C-6. Photo Beam D-6 After Dynamic Load of 29.9 Kips. 59 C-7. Photo Beam D-7 After Dynamic Load of $26.6 \mathrm{Kips} .60$ C-8. Photo Beam S-1 After Static Load of 23 Kips . 60 D-1. Load-Deflection Curve Beam S-I . . . . . . . 62 D-2. Load-Strain Curve Beam S-1 . . . . . . . . 63 D-3. Load-Deflection Curve Beam S-2 . . . . . . . 70 D-4. Load-Strain Curve Beam S-2 . . . . . . . . 71 E-1. Dynamic Response Beam D-1... . . . . . . 73 E-2. Dynamic Response Beam D-2 . . . . . . . . . 74 E-3. Dynamic Response Beam D-3 . . . . . . . . . 75 E-4. Dynamic Response Beam D-4 . . . . . . . . . . 76 E-5. Dynamic Response Beam D-5. . . . . . . . . . 77 E-6. Dynamic Response Beam D-6. . . . . . . . 78 E-7. Dynamic Response Beam D-7 . . . . . . . . . . 79 E-8. Buildup and Delay Time Beam D-6. . . . . . . 80 E-9. Equivalent Spring Mass System . . . . . . . 81 E-10. Theoretical and Experimental Deflection Beam $\mathrm{D}-4$. . . . . . . . . . . . . . 84 


\section{NOMENCLATURE}

A . . Arbitrary constant; cross sectional area

$A_{S}^{\uparrow} \cdot$. Area of mild steel reinforcement

$A_{\text {SS }} \cdot$. Area of prestress steel

a . . Distance from top of beam to the neutral axis

B . . . Frequency of forcing function

$\mathrm{B}^{\circledR}$. . Arbitrary constant

b . . Width of beam

$\mathrm{C}_{\mathbf{S}}^{\prime}$. . Total compressive force in mild steel

$\mathrm{C}_{\mathrm{C}}$. . Total compressive force in concrete

c. . Viscous damping coefficient

c . : Critical damping

D . . . Designation of dynamic test member

d . . Distance from top of beam to c.g. of prestress steel

$d^{\prime}$. . Distance from top of beam to c.g. of mild steel

$\mathrm{E}_{\mathrm{C}}$ - . Modulus of elasticity of concrete

$\mathrm{E}_{\mathrm{S}}$ - - Modulus of elasticity of steel

$\mathrm{E}_{\mathbf{S}}^{\prime} \cdot$. Plastic modulus of prestress steel

$\mathrm{e}_{\mathrm{c}} \cdot$. Concrete strain

$\mathrm{e}_{\mathrm{ci}}^{\mathrm{t}}$. . Initial concrete strain top

$\mathrm{e}_{\mathrm{ci}}^{\mathrm{b}} \cdot$. Initial concrete strain bottom

$e_{o}$. . Strain at maximum concrete stress

$\mathrm{e}_{\mathrm{s}} \cdot$. Strain in prestress steel 
$\mathrm{e}_{\mathrm{u}}$. - Ultimate concrete strain

$e_{y p} \cdot$. Yield strain in prestress steel

$f_{a}$. . Stress in prestress steel prior to loading

$f_{b}$. . . Stress in prestress steel after loading

$\mathrm{f}_{\mathrm{c}} \cdot$. Ultimate concrete compressive stress

$f_{c}^{\prime \prime}$. . Maximum concrete compressive stress

$\mathrm{f}_{\mathrm{ci}}^{\mathrm{t}}$. . Initial concrete compressive stress top

$\mathrm{f}_{\mathrm{ci}}^{\mathrm{b}}$. . Initial concrete compressive stress bottom

$\mathrm{f}_{\mathrm{si}}$ 。 Initial stress in prestress steel

$\mathrm{f}_{\mathrm{si}} \cdot$. Initial stress in mild steel

$\mathrm{f}_{\mathrm{su}}$. . . Stress in prestressing steel at ultimate load

$\mathrm{f}_{\mathrm{v}}$. . . Stress in mild steel

$\mathrm{f}_{\mathrm{y}} \cdot$. Yield stress in mild steel

$f_{y p} \cdot$. Yield stress in prestressing steel

$F(t)$. Forcing function

$F_{1}$. - Force on beam after system comes to rest

h. . Depth of beam

I. . . Moment of inertia about $\mathrm{X}-\mathrm{X}$ axis

k. . Beam stiffness

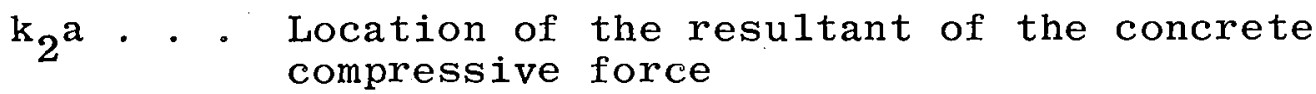

$k_{3}$. - Ratio of maximum stress to cylinder strength

L . . L Length of span

M. . . Resisting moment

$M_{n}$. . Net cracking moment

$M_{n p}$ - . Net increase in moment post cracking range

Mo . Moment to produce yielding 


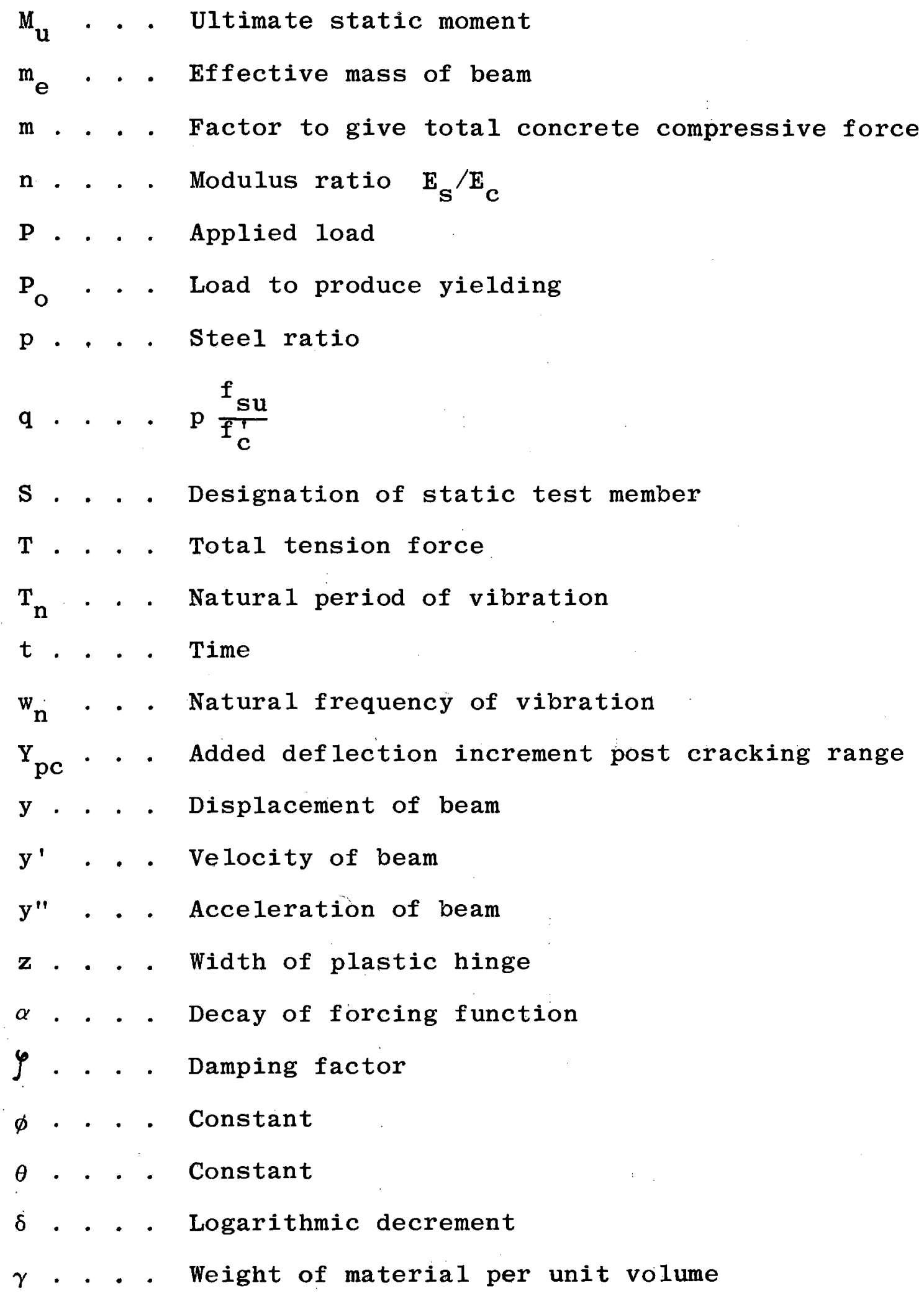




\section{CHAPTER I}

\section{INTRODUCTION}

\subsection{Genera1}

The use of prestressed concrete beams in blast resistant construction has seen limited applications due to the lack of knowledge as to the response of these members when subjected to a highly impulsive load. Studies by the Naval Civil Engineering Laboratory (1) indicate that prestressed concrete beams may be used to advantage for this type of construction.

This investigation is justified by advantages which can be achieved through the use of prestressed concrete; little or no permanent deflection at loads near their ultimate load; savings in steel, concrete, and clearance that can be obtained through the use of these members.

\subsection{Statement of the Problem}

The response of pretensioned prestressed concrete beams subjected to impulsive loads concentrated at the third points is investigated. Many static tests have been conducted on prestressed concrete beams, but very little information is to be found on the dynamic response of these members. 
The purpose of this study is to determine experimentally the general behavior of prestressed members.

\subsection{Historical Review}

The literature survey was not limited to impulsive testing of prestressed concrete beams but also included impulsive testing of concrete and steel specimens.

The earliest destructive experiments on engineering materials consisted of falling weights stopped suddenly by a wire attached to an anvil (2). These tests were made in England by Dr. John Hopkinson in 1872 and later refined by his son, Bertram, who observed that iron wire could be stressed beyond its static breaking load and still remain elastic (3), provided the duration in which the stress exceeded the elastic limit was less than .001 second. Eaton Hodgkinson worked on the "horizontal impact on a beam" in which he determined the effective mass of a beam for calculating the common velocity of the striking body and of the beam immediately after impact to be one-half of the mass of the beam (4).

The effect of velocity of impact on the resulting distortion energy was investigated in a series of tests by Charpy and Cornu-Thenard in 1917 (5). They varied the velocities of impact from 2.5 to 21.5 feet per second, and were able to measure no appreciable difference so discounted velocity as being of any great importance.

The United States Bureau of Standards, in 1929, tested 
reinforcing bars purchased on the open market in an effort to determine brittleness. Under the testing procedures used (dropping hammers of various weights), none of the bars was ruptured but all developed permanent strains (6). In 1936, Mann (7) invented an impact machine consisting of a wheel with retractable horns which were released at the desired velocity. Breaking energy was measured by a pendulum which moved as a result of the impulses imparted to it through the test specimen. Formulas were derived for the energy of rupture.

The first combination of electric resistance strain gages, oscillographs, and high speed cameras to measure dynamic strains in tensile test specimens occurred in 1944 (8).

These were used by Fehr with an impact machine similar to the one developed by Mann.

After World War II renewed interest in impulsive loading was to come into great prominence. The atomic era increased the interest in dynamic loads and instrumentation had been perfected which could measure the experimentally applied loads. From Germany, Fink (9), in 1949, presented a study made on mild solid steel specimens loaded with impulsive loads. The instrumentation used in these tests consisted of oscilloscope and strain sensitive carbon elements.

In 1952, Vivian, in England, designed a tension impact test for steel specimens (10). Falling weights were used 
to break the specimens and an air cushion was used to measure the residual energy. An attempt was made to distinguish between uniform energy and necking energy.

Penzien and Hansen (11) at the Massachusetts Institute of Technology reported upon dynamic yield stress in concrete beams. They found an increase of approximately 35 per cent for dynamic loading.

Mylrea studied impact on reinforced concrete beams at the University of Delaware (12). Beams with different grades of reinforcing steel were tested. He found that rail steel was as resistant to impact as structural grade stee1.

Speth (13) reported on bombing damage to reinforced concrete. He showed that the kind of reinforcement influenced the resistance very little, while the concrete quality had a significant influence upon resistance.

Massachusetts Institute of Technology compared the static and dynamic elastic behavior of reinforced concrete beams. These beams were loaded dynamically with the use of a gas cylinder (14).

Mavis and Richards (15) at Carnegie Institute of Technology reported on reinforced concrete beams with different grades of reinforcement. They reported that damage and permanent set in all beams reinforced with structural grade steel exceeded the damage and permanent set in beams reinforced with hard grade steel.

In a further report, Mavis and Greaves (16) reported 
on a series of experiments involving pairwise destructive tests of beams reinforced with intermediate or structural grade steel compared with beams reinforced with hard grade steel.

Stewart (17) reported on individual reinforced concrete beams, loaded with a dynamic load to destruction, reinforced with various grades of steel and different percentages of steel.

The literature survey has produced very few reports on dynamic testing of prestressed concrete beams. Magnel (18), in Belgium, reported on a few impact tests that he performed. His tests consisted of dropping varying weights from different heights on prestressed members. The British Building Research Station (19) has also performed a few tests on prestressed concrete members but these tests do not appear to be relevant to this project. In a further report (20) the British have listed a series of general observations for prestressed and reinforced concrete members.

The U. S. Naval Civil Engineering Laboratory has completed a series of tests on prestressed concrete beams, both post-tensioned (21) with straight unbonded bars and pretensioned (I) members. In this testing program the beams were loaded with a simulated blast load (22). They reported that permanent deflections are not produced by dynamic loads of less than 85 per cent of failure load; that there was no tensile stress produced by dynamic 
loading in the top fiber of the beam; and that a single degree of freedom system may be used to represent the beam in the elastic range.

Wadlin and Stewart (23) reported on a series of tests that were conducted at Carnegie Institute of Technology. They compared prestressed and conventionally reinforced concrete beams of the same size subjected to static and to cyclical impulsive loadings. 
CHAPTER II

\section{EXPERIMENTAL WORK}

\subsection{Dynamic Testing Machine}

The dynamic testing machine used for this series of tests was originally constructed in 1958 for a testing program on concrete beams reinforced with rail-bar steel. It is similar to the machine described by stewart in his thesis. During the spring of 1966 the machine was completely rebuilt and the instrumentation for recording all dynamic measurements was completely changed. All measurements were recorded directly on magnetic tape, the output of which was fed into a strip chart recorder to obtain a printout of the continuous functions that had been measured.

A schematic diagram of the dynamic testing machine is shown in Figure 1. The machine is composed of two structural groups; the static or supporting structure, and the moving or load applying structure. The supporting structure consists of the base beam (A), the reaction support column (B), the guide columns (C), the column bracing arrangement (D), and the reaction rings (H). The moving structure designed to apply the dynamic loading to the test specimen (K) consists of encased springs ( $F$ ), the needle 


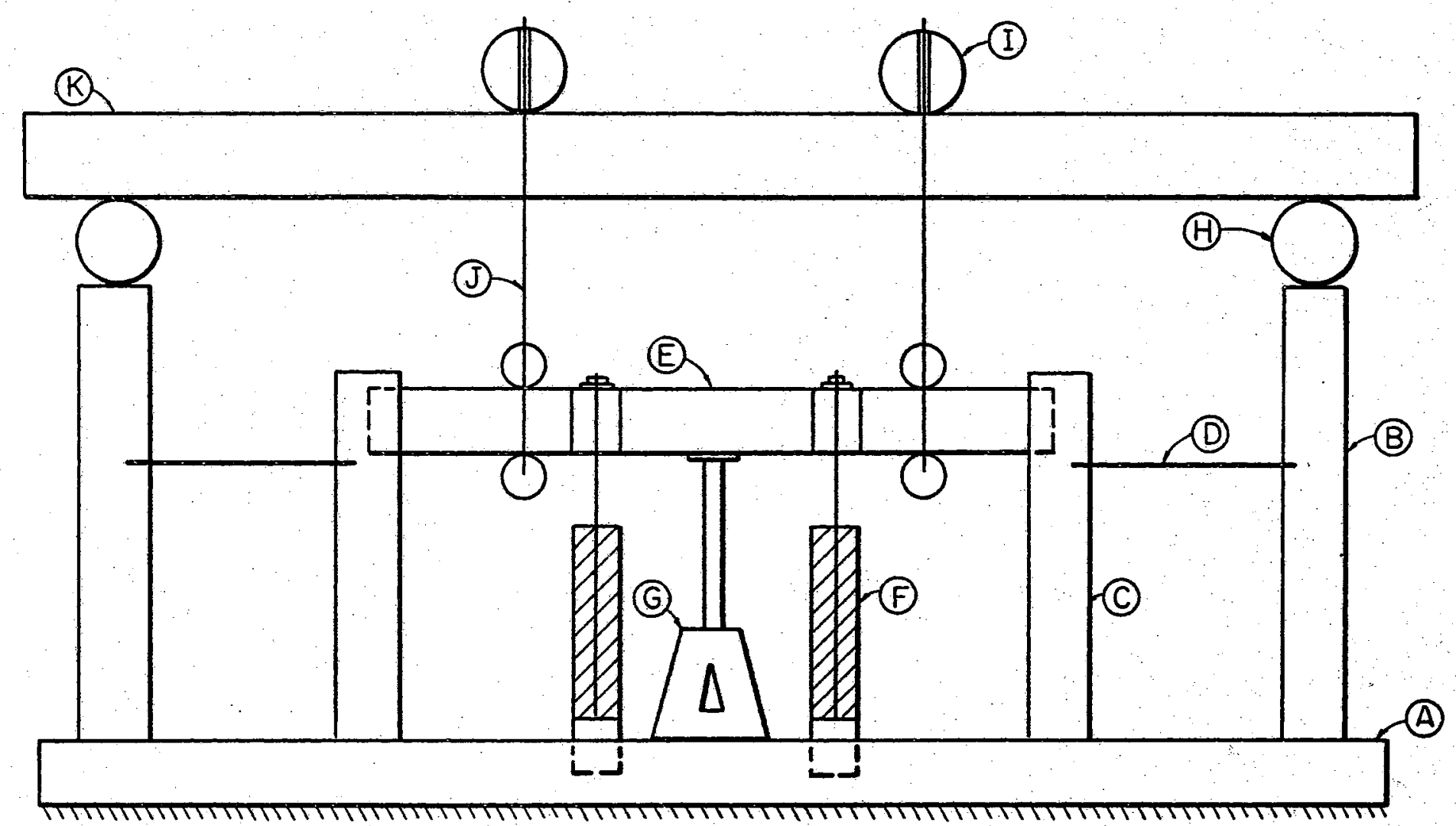

Figure 1. Schematic Diagram of the Dynamic Testing Machine 
beam (E), the loading yoke (J), and the load rings (I) which apply the load to the specimen. Prior to each test the trip jack (G) holds the entire dynamic load.

The machine was designed to test beams having a center to center span of 8 feet 0 inches and weighing up to 2000 pounds. The load is applied at the third points of the specimen. The total height of the machine from floor to the top of the beam specimen is 6 feet 2 inches, the length is 9 feet 0 inches and the width is 3 feet 6 inches.

\subsection{Instrumentation}

The instrumentation used in this testing program was designed to record all dynamic measurements on magnetic tape. As a supplement, the dynamic measurement of the load ring was recorded on film through the use of a high speed camera.

The load and reaction values to be recorded were obtained from calibrated steel rings upon which electric strain gages had been mounted. Each of the rings consisted of a Wheatstone bridge, in which the compression zone gages were wired in opposite legs of the bridge and the tension zone gages completed the bridge. Thus, all legs of the bridge added together to provide the necessary change in voltage to be measured.

The deflection of the beam was measured with a Sanborn (24v DCDT) displacement transducer. A minor problem was encountered with the output of the transducer, the 
maximum output voltage occurring with maximum displacement of the transducer core amounted to 13 volts, whereas the maximum voltage input to the magnetic tape recorder was limited to 3 volts. To overcome this, two resistors, one $9 \mathrm{~K}$ and the other $1 \mathrm{~K}$ were connected in series across the output of the transducer. The input of the magnetic tape recorder was then measured across the $1 \mathrm{~K}$ resistor. The wiring diagram of this is shown in Appendix A, Figure A-1. The resistor setup performed with no difficulties whatsoever.

Two strain gages were mounted on the top face of the beam to measure the compression of the concrete. These two active gages were connected with two inactive gages to form a bridge. This is shown in Appendix A, Figure A-2. The output of this bridge was fed into the recorder through an amplifier.

A11 wire used for the circuits was shielded cable, but it was found necessary that the shielding on all lines be connected to the low side on all of the input lines to the recorder. This is shown on the sketches of the various circuits in Appendix A. The transducer was extremely sensitive to this problem.

The entire instrumentation setup consisted of four major units; the recorder, the power supplies, the amplifiers, and the Wheatstone bridges. In setting up the instrumentation a problem in securing a common ground occurred several times. It was found that all units had to 
be connected to one and only one ground. Once a common ground was secured the dynamic testing machine was also grounded; this eliminated static that had been recorded from the reaction ring before grounding because the testing machine had been acting as an antenna.

Each of the bridges received power from a D.C. power supply (Harrison $801 \mathrm{C}$ ) which had been mounted in the recording cabinet. The voltage change measured at the bridge was fed into a data amplifier (Sanborn 8875A) and then onto the magnetic tape. The recording system used was a Sanborn model 3907A Magnetic Data System. This system provided the capability of recording at a high speed and playing the output back at a much slower speed. The output of the tape system was fed into a Sanborn model 320 strip chart recorder for a visual plot of the data. The tape system provided a maximum reduction factor of 32 from input to output.

In addition to the tape system, the unbalanced bridge voltage of the load $r$ ing was fed into an oscilloscope where it was displayed as an oscillating dot of light on the tube face. This was done in order to have a correlation between the film record of the action and the bridge output. Through an arrangement of mirrors, shown in Figure A-5, Appendix A, the image of the oscilloscope was reflected onto the front lens aperture of the high-speed motion picture camera. The camera was running at approximately 2000 frames per second. 
In order that the trace of the load ring be in correct sequence with the pictures of the beam the input to the oscilloscope had to be taken from the output of the amplifier. The output of the recorder was first used but it was found that the delay time between record and play back (approximately $1 / 60$ second) of the recorder gave a delay of the dot action on the film. No problem was encountered after the input was taken from the amplifier.

The camera was oriented in such a manner that the oscilloscope image was displayed on the film above the pictorial action of the beam specimen. Deflection of the test beam was also observed by using a fixed reference line above the dynamic testing machine. The reference line appeared on the photographic record as a white strip above the specimen.

\subsection{Load and Reaction Rings}

The reaction ring at the left end of the beam was instrumented for measurement of the dynamic reaction. The ring was a continuous ten inch length of six-inch diameter extra strong steel pipe plug-welded to a steel plate. Three foil strain gages were mounted in the compression zone on both sides of the inside of the ring and in the tension zone on the outside of the ring, all at mid-height, a total of twelve gages. Each set of three gages was connected in series to form one leg of the Wheatstone bridge. This is shown in Figure A-4, Appendix A. 
The load ring at the left hand third point was also instrumented for measuring the applied dynamic load. The ring was an eight inch section of double extra strong steel pipe. The eight inch length was cut twice to make three sections. The intention of this was to provide more sensitivity for the ring. In this program only the middle third of the ring was required for the loads used. Four gages on the ring formed the bridge used for measurement of the applied load, this is shown in Figure A-3, Appendix A. Before the testing program was started and during the program, both rings were calibrated to see that their characteristics did not change. The rings were placed in a Baldwin testing machine and supported as they were during the testing program. The load was applied to the rings and a trace of the load was obtained from the strip recorder. Repeated loading of the rings provided a straight line calibration trace. Calibrations performed during the testing program showed no change from the original calibrations.

\subsection{Description and Construction of Test Members}

Nine simply supported pretensioned concrete beams, 8 inches wide by 10 inches deep and 9 feet long, were tested. Two were tested statically and seven were tested dynamically. The clear span length was 8 feet 0 inches. They were designed to carry a total moment 360,000 inch pounds. This design was based upon static equilibrium. High strength concrete with a minimum 28 day strength of 5,000 
pounds per square inch was specified.

Five of the prestressed beams were cast July 11,1966 and the remaining four were cast July 13, 1966 by the Structural Concrete Products Corporation at their Auburn, Maine plant. The mix proportions used were those developed by Structural Concrete Corporation for use in prestressed concrete building construction. As supplied by the Structural Concrete Corporation, the mix per cubic yard of concrete consisted of:

$\begin{array}{lr}\text { water } & 34.75 \text { gals. } \\ \text { cement, type III } & 752 \text { lbs. } \\ \text { sand } & 11501 \mathrm{bs} . \\ \text { coarse gravel } & 1900 \mathrm{lbs} .\end{array}$

which produced a slump of two inches.

Six standard test cylinders were cast for each of the two casting days. These cylinders were tested upon release of the prestressing strands, at 7 days and at 28 days. The ultimate concrete compressive strength is shown in Table I. This value is the average of two cylinders.

The beams were reinforced with 5, Roebling $1 / 4^{\prime \prime}$ ASTM Grade 7-wire uncoated stress-relieved prestressed concrete strands, all placed in the bottom of the beam. Two No. 3 deformed reinforcing bars were included in the upper portion of the beam. The beams also were reinforced with No. 3 stirrups placed 6 inches center to center. The stressstrain curve for the prestressing steel is given in 
Figure 2. The dimensions of the beam and location of the reinforcement is shown in Figure 3 .

TABLE I

ULTIMATE COMPRESSIVE STRENGTH OF CONCRETE

\begin{tabular}{ccc}
\hline Mix & Age & $\begin{array}{c}\text { U1t Compressive } \\
\text { Strength Psi }\end{array}$ \\
\hline \multirow{2}{*}{ July 11 release (1 day) } & 3400 \\
& 7 days & 5378 \\
& 28 days & 5777 \\
July 13 & release (1 day) & 4300 \\
& 7 days & 5650 \\
& 28 days & 5976
\end{tabular}

The beams were identified by serial numbers and letters. The first letter described the manner of testing; $\underline{D}$ for dynamic and $\underline{S}$ for static. The letter was followed by a number which designated the order of testing. Thus, D-3 was the third beam tested dynamically.

\subsection{Test Procedures}

Static and dynamic flexural tests were both employed in this program. An attempt was made to determine the dynamic load at which the beams were on the verge of failure. This ultimate dynamic load then could be compared with the ultimate static load.

One prestressed concrete beam from each of the separate castings was tested to destruction in a static testing 


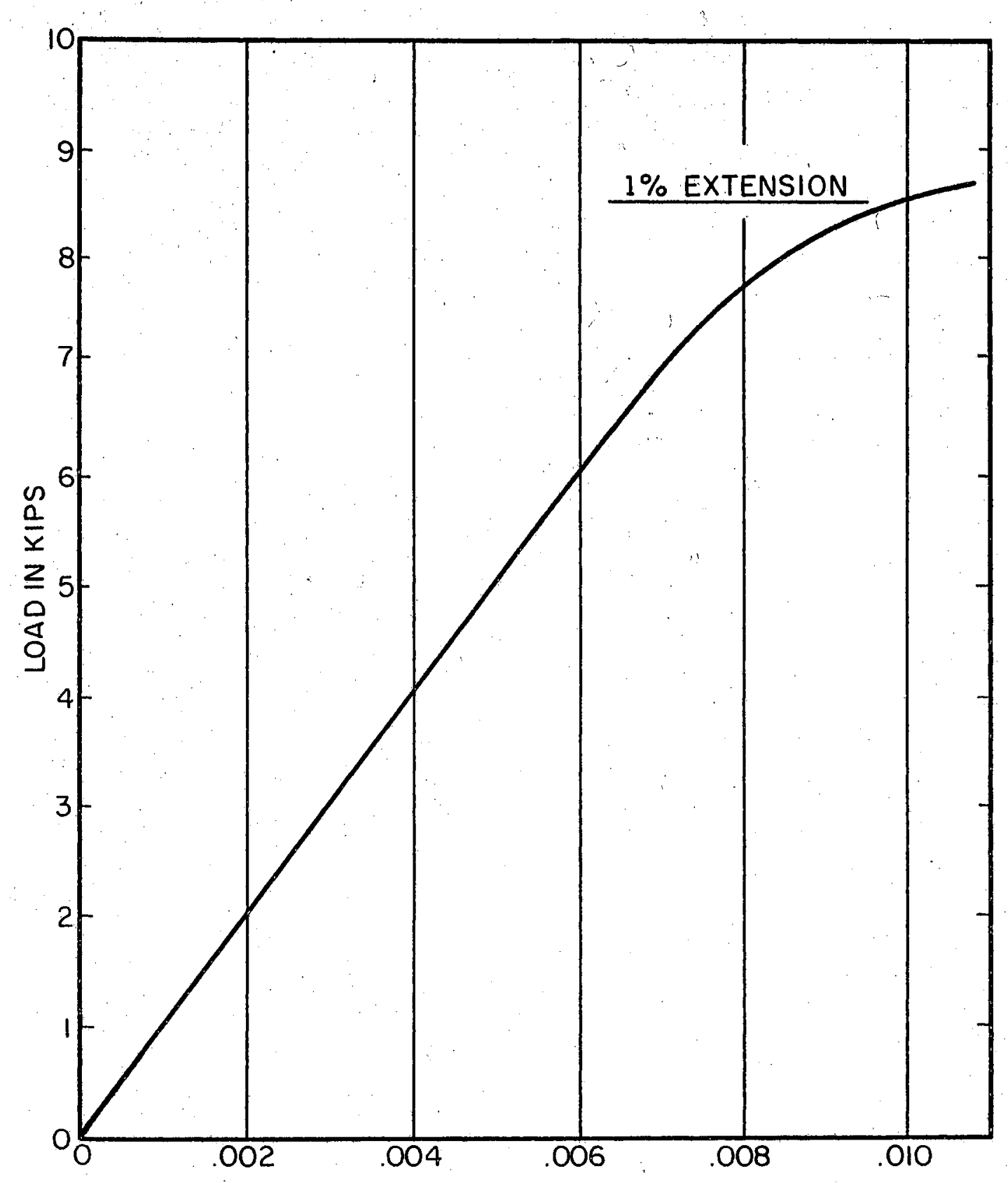

1/4" Dia. ASTM Grade 7-Wire Uncoated Stress-Relieved Prestressed Concrete Strand

(Courtesy Colorado Fuel and Iron Corporation)

Figure 2. Stress-Strain Diagram for Prestress steel 


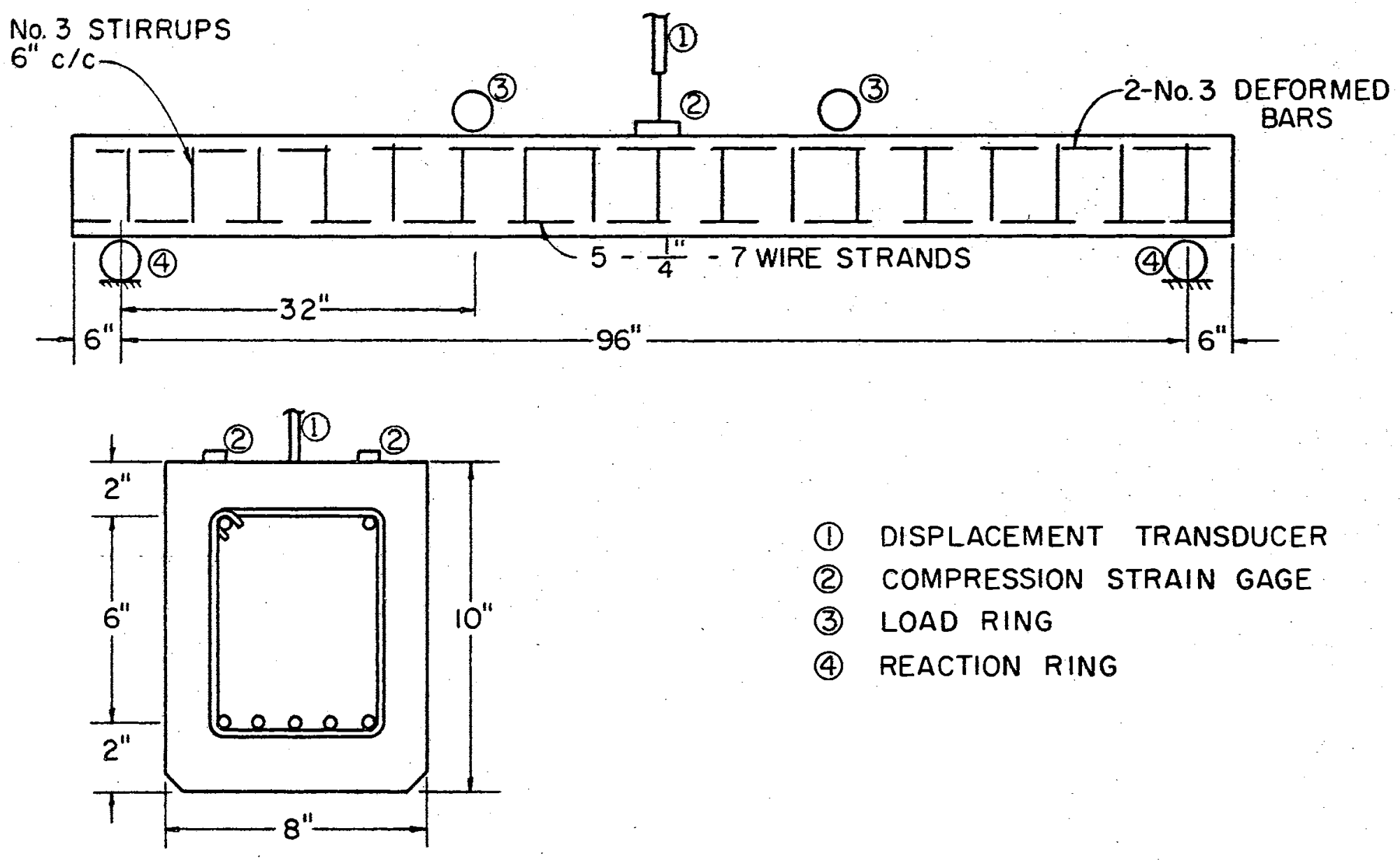

Figure 3. Pretensioned Concrete Beam Dimensions Including Instrumentation Locations 
machine; the remaining beams were tested dynamically. The static tests were conducted before the dynamic testing program began. This was done to compare the strength of the test specimen against the design strength; and to determine the magnitude of the compressive strains in the extreme fiber of the concrete. This information was needed in order to determine the voltage that could be used in the Wheatstone bridge measuring the compressive strains.

Static Tests. Strain gages were mounted on the upper surface of the beam specimens. The beams were tested to destruction in a 150,000 pound compression machine by applying the load in 1000 pound increments to the thirdpoints of the beams. The midspan deflection and the strains from the two gages were recorded. A plot of loaddeflection and load strain for each of the beams is shown in Appendix D.

Dynamic Tests. The dynamic testing program was started using the information obtained from the static testing program. It was not possible to cause dynamic failure with a load equal to the static failure load; the loading had to be increased to obtain the dynamic failure.

Some loads that were applied were greater than the ultimate dynamic strength of the beams; these resulted in spectacular failures as far as the films were concerned. The actual procedure of dynamic testing will be outlined so that the reader may understand how the testing was done. 
1. Load and reaction rings were calibrated, then mounted on the testing maching.

2. The top surface of the beam was ground to a smooth finish and the strain gages applied.

3. The beam was centered on the reaction rings.

4. With the aid of a hydraulic jack, one end of the beam at a time was raised off the reaction ring. A $3 / 8$ inch plate covered with a thick coat of plaster of Paris on its top surface was placed on the reaction ring. The jack was released so that the beam would seat firmly in the plaster of Paris.

5. Plates were then placed on the top surface of the beam at the third points in the same manner to act as bearing plates for the load rings.

6. The load rings were then slipped over the loading yoke rods. The nuts to hold these rods were not put on until the last in case the trip for the loading mechanism might slip.

7. The shielded cables to the strain gages mounted on the top face of the beam were connected and all leads soldered. All other cables were connected with Cannon connectors.

8. A plate to anchor the displacement transducer rod was cemented to the top surface of the beam between the two compression gages.

9. The middle third of the beam was painted with 
white latex paint to provide a better contrast in the pictures. The center line was marked with a black triangle and the beam's serial number was added.

10. The magnetic tape recorder and oscilloscope were turned on to allow at least one hour warm up time. All voltages of the power supplies were checked.

11. The transducer rod was connected and the case holding the transducer adjusted to the correct height to obtain maximum negative deflection voltage. Thus, during the test the total stroke of the rod would have a maximum range from the maximum negative to the maximum positive voltage.

12. A black backdrop screen was moved into place behind the beam and testing machine. This, along with the white surface of the beam, provided the contrast needed in the pictures.

13. The view of the camera was checked and a strip of focusing film used to check the focus of the lens.

14. A light in position to illuminate a sit in the backdrop was turned on and the alignment of the oscilloscope dot with the slit was checked. This acted as a reference to measure the travel of the load ring oscilloscope dot during testing.

15. Using two hydraulic jacks, the needle beam was 
raised into position, compressing the springs used to apply the load.

16. The trip jack was centered on the base beam under the needle beam and its lifting shaft was raised into position.

17. The hydraulic jacks were simultaneously released placing the entire load of the springs on the trip jack. The needle beam was checked to see that it was level. If not, steps 15,16 , and 17 were repeated until the needle beam remained leve1.

18. A plate was inserted between the load ring and the load ring bearing plate so that only the middle third of the load ring was in contact with the bearing plate. The nuts were now put on the loading yoke rods to hold the load rings in place.

19. All measurements were checked to make sure that the loads were applied exactly at the third points.

20. The film was placed in the camera and the photo flood lights were turned on.

21. A check was made to see that the amplifiers were set at the correct readings and to see if all bridge power supplies were connected. The magnetic tape recorder was turned to record.

22. The trip on the trip jack was set and a long 
steel rod inserted into the jack handle.

23. The camera operator started a count and turned the camera on at the count of three.

24. When the count reached five, the jack was tripped and the test was conducted.

25. The camera automatically shut off after 100 feet of film had passed.

26. The tape recorder was turned off; Polaroid pictures were taken of the beam in the deflected position and the photo lights turned off.

27. If the beam had not been completely destroyed, the needle beam was raised to remove any load remaining and the permanent deflection was measured.

28. The film was removed from the camera and the bridges were disconnected.

29. The specimen was removed from the loading machine.

30. The slower speed cards were inserted into the tape recorder and a trace of the Wheatstone bridges was recorded on the strip recorder. 


\title{
CHAPTER III
}

\author{
THEORY
}

\subsection{Static Load-Deflection Curve}

To simplify the calculation of the static load-deflection curve the following assumptions were made:

1. A plane section before bending remains plane for all loadings.

2. Concrete tension stresses are negligible.

3. The stress-strain relationship for concrete in compression is given by idealized curve (24) as shown in Figure 4.

4. The concrete and mild steel strains are constant throughout the portion of the beam in which yield has occurred.

5. Ultimate load and deflection are reached when the outer fibers of concrete in compression reach an ultimate strain.

6. Deflections due to shear strains and diagonal tension cracking are neglected.

With these assumptions the concrete stresses after the prestressed loads were transferred to the beam were taken as: 


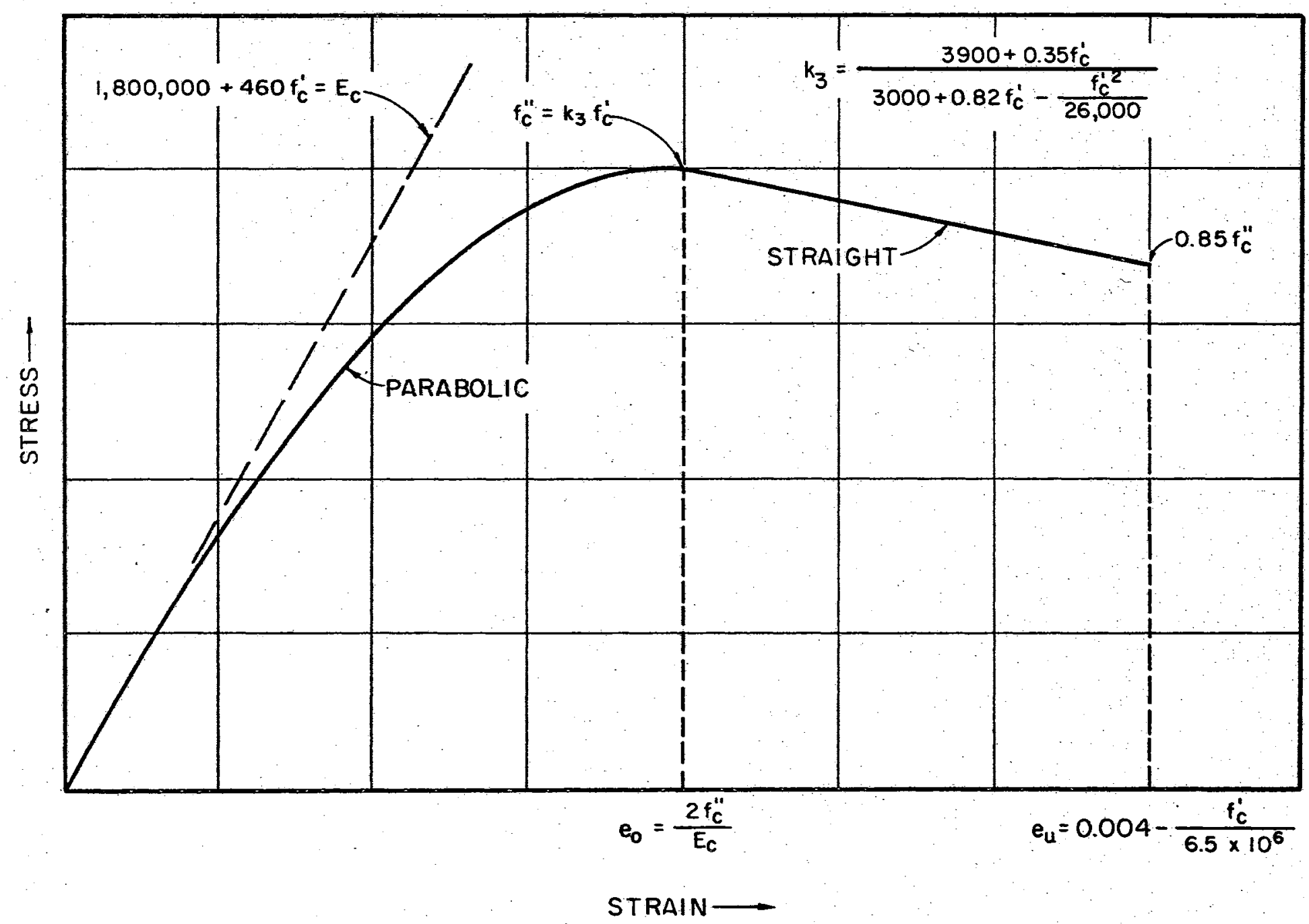

Figure 4. Idealized Stress-Strain Diagram for Concrete 
a. compression stresses in the top fiber $f_{c i}^{t}=0$

b. compressive stresses in the bottom fiber, $f_{\mathrm{ci}}^{\mathrm{b}}=1044 \mathrm{psi}$

As the beam was loaded on the top surface, compressive stresses were increased above the neutral axis and the compressive stresses were reduced below the neutral axis. Stress diagrams for the two conditions are shown in Figure 5 .

Prestress Steel

The idealized stress-strain diagram for the prestress steel is shown in Figure 6. Point "a" represents the level of stress just prior to loading, point "b" the stress level in a loaded condition. The value of the steel stress was then computed as follows:

a. Elastic Range

$$
f_{b}=f_{a}+\frac{(d-a)}{a} e_{c} E_{s}
$$

where $d$ and a are defined in Figure 5 .

b. Plastic Range

When the beam was loaded into the plastic range the modulus of elasticity was reduced to $\mathrm{E}_{\mathrm{S}}^{\prime}$.

$$
f_{b}=f_{y p}+\left[\frac{f_{s i}}{E_{s}}+\frac{(d-a)}{a} e_{c}-e_{y p}\right] E_{s}^{\prime}
$$

Mild Compression steel

The stress in the compression steel within the elastic 


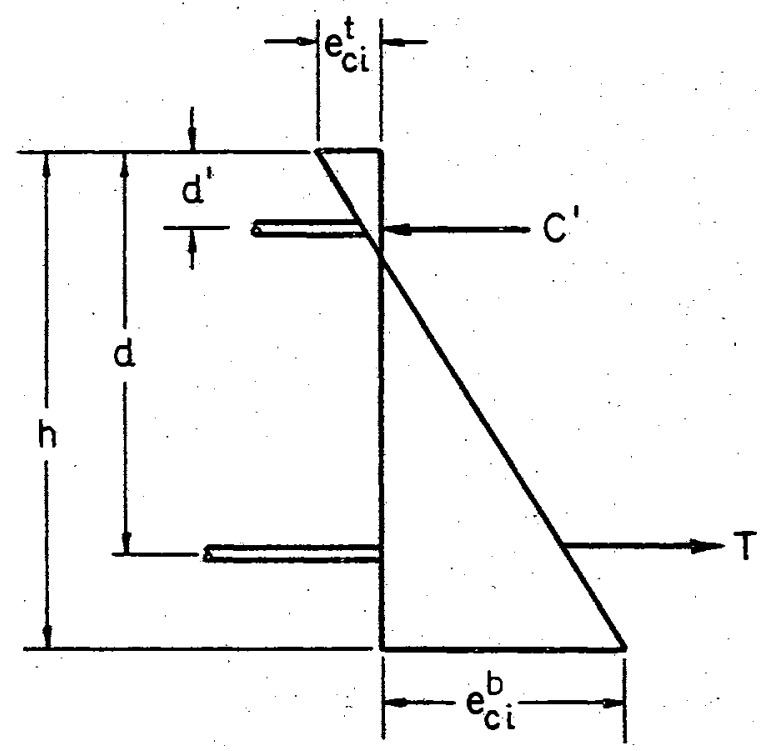

PRE-LOADING

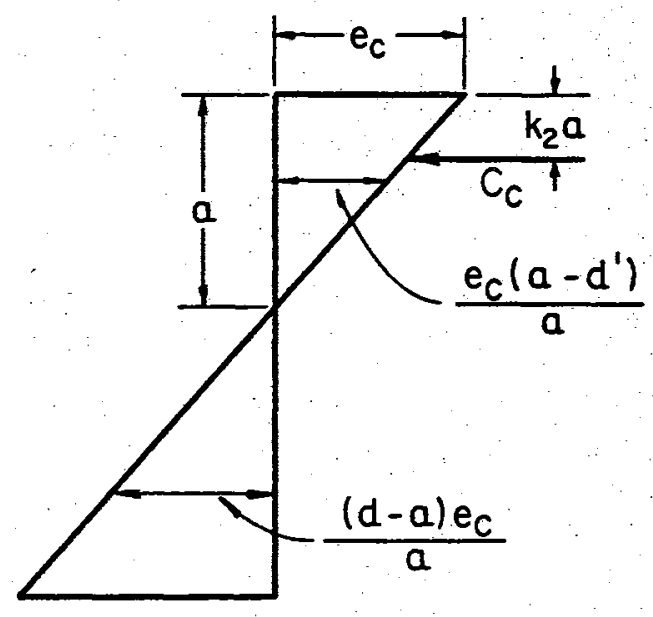

LIVE - LOAD

Figure 5. Internal Forces and Strains of Beam Cross-Section 


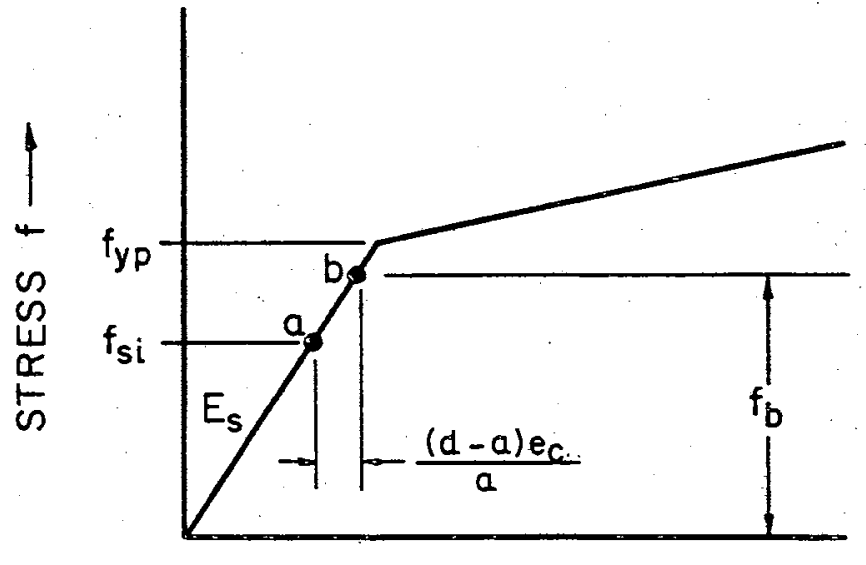

STRAIN. e $\longrightarrow$

ELASTIC RANGE

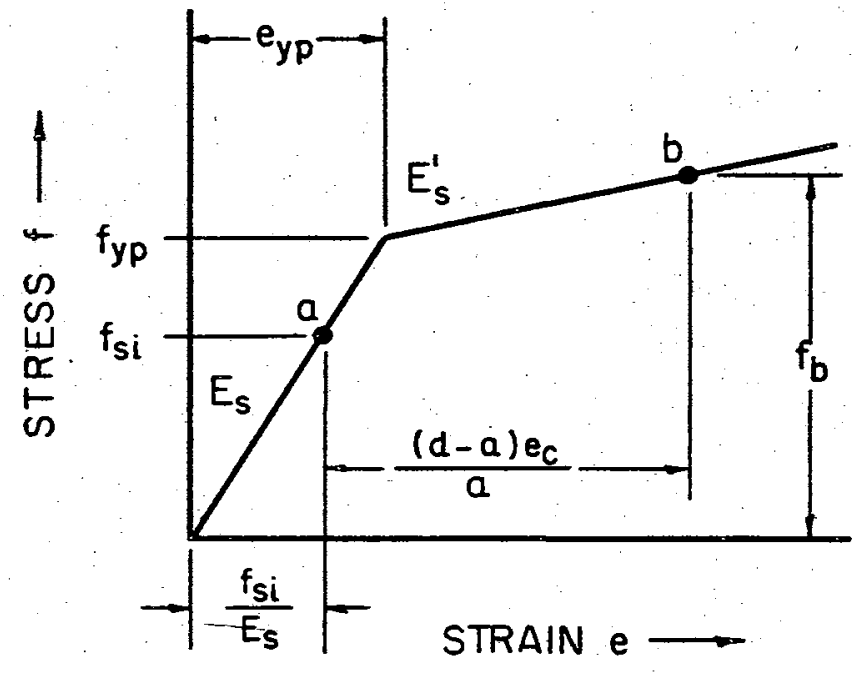

PLASTIC RANGE

Figure 6. Idealized Stress-Strain Diagrams for Prestress Steel 
range was

$$
f_{v}^{p}=f_{s i}^{\prime}-e_{c} \frac{\left(a-d^{\prime}\right)}{a} E_{s}
$$

where $f_{s i}$ was the stress in the compression steel at preload.

In the plastic range, the stress was assumed to be a constant, $f_{v}^{\prime}=-f_{y}$, the yield strength of the steel.

The forces acting on a free body diagram were computed by multiplying the area of the steel by the stress in the steel.

The total tension force in the tension steel is:

$$
T=A_{s s}\left[f_{s i}+\frac{(d-a)}{a} e_{c} E_{s}\right]
$$

in the elastic range and

$$
T=A_{s s}\left\{f_{y p}+\left[\frac{f_{s i}}{E_{s}}+\frac{(d-a)}{a} e_{c}-e_{y p}\right] E_{s}^{\prime}\right\}
$$

in the plastic range.

The total compression force in the compression steel is:

$$
C_{s}^{\prime}=A_{s}^{\prime}\left[f_{s i}-e_{c} \frac{\left(a-d^{\prime}\right)}{a} E_{s}\right]
$$

in the elastic range and

$$
C_{s}^{\prime}=A_{s}^{\prime}\left(-f_{y}\right)
$$

in the plastic range.

The compression force of the concrete, $\mathrm{C}_{c}$, was expressed as (25): 


$$
\begin{aligned}
c_{e} & =m b a \\
m & =\frac{1}{3 e_{c}}\left[e_{c} \leq .85 f_{c}^{\prime \prime}\right. \\
m & =\frac{1}{2 e_{c}}\left[\frac{f_{c}^{\prime \prime}\left(3 e_{c}+f_{c}\right)-f_{c} e_{o}}{3}+\left(0 \leq e_{c} \leq e_{c}\right)\right. \\
m & \left.\left(e_{c}-e_{o}\right)\right]\left(e_{o} \leq e_{c} \leq e_{u}\right)
\end{aligned}
$$

where

$$
f_{c}^{\prime \prime}=\left[\frac{3900+0.35 f_{c}^{\prime}}{3000+0.82 f_{c}^{\prime}-\frac{f_{c}^{2}}{26000}}\right] f_{c}^{\prime}
$$

and

$$
\mathrm{e}_{\mathrm{o}}=2 \mathrm{f} \stackrel{\mathrm{c}}{\mathrm{c}} / \mathrm{E}_{\mathrm{c}}
$$

The modulus of elasticity of the concrete was taken as:

$$
\mathrm{E}_{\mathrm{c}}=1,800,000+460 f_{\mathrm{c}}^{\prime}
$$

and the ultimate concrete strain as

$$
e_{u}=0.004-\frac{f_{c}^{\prime}}{6.5 \times 10^{6}}
$$

To locate the neutral axis the sum of all forces was set equal to zero. This provided a quadratic equation in terms of $a$.

$$
\mathrm{T}+\mathrm{C}_{\mathrm{s}}^{\prime}+\mathrm{C}_{\mathrm{c}}=\mathbf{0}
$$

Summing moments about the tension steel gave the resisting moment .

$$
M=C_{s}^{\prime}\left(d-d^{\prime}\right)+C_{c}\left(d-k_{2} a\right)
$$

The applied load was found from the equation $P=\frac{3 M}{L}$. 
Deflection at midspan could be found by any of the many methods for an elastic member, provided the beam had not yielded. After the beam yielded the unit rotation diagram method was adapted (25). Figure 7 shows the loaded beam, the moment diagram, and the unit rotation diagram at ultimate load. As calculated in Reference 25, the width of the plastic hinge was:

$$
z=\frac{1}{3}+\frac{2}{3} \quad\left(1-\frac{P_{O}}{P}\right)
$$

and the maximum ordinate of the unit rotation diagram was $\left(e_{c}+e_{s}\right) / d$. The midspan deflection of the beam was:

$$
\Delta_{c 1}=\frac{M_{O} L^{2}(1-z)^{2}}{12 \mathrm{EI}}+\frac{\left(e_{c}+e_{s}\right) \mathrm{zL}^{2}(1-0.5 \mathrm{z})}{4 \mathrm{~d}}
$$

An example of calculating the theoretical static load deflection curve up to ultimate load is given in Appendix D.

\subsection{Dynamic Deflection - Time Curve}

The differential equation of motion of a simple supported beam was converted to a single degree of freedom system and solved.

$$
m_{e} \ddot{y}+c \dot{y}+k y=F(t)
$$

The forcing function $F(t)$ produced by the Dynamic Testing Machine was a decaying cyclical function and can be expressed as

$$
F(t)=F_{1}\left(1-e^{-\alpha t} \cos B t\right),
$$




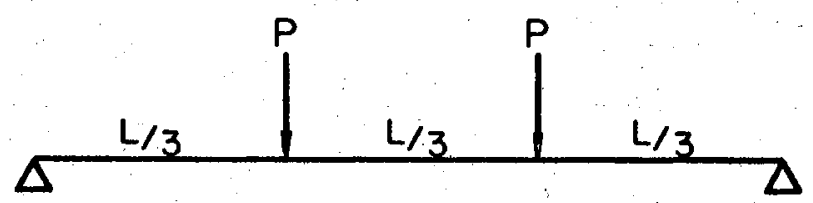

BEAM WITH SYMMETRICAL LOADING

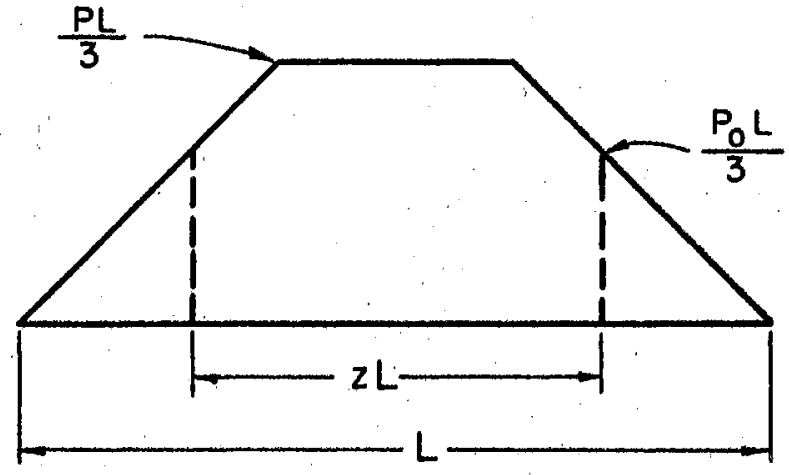

MOMENT DIAGRAM

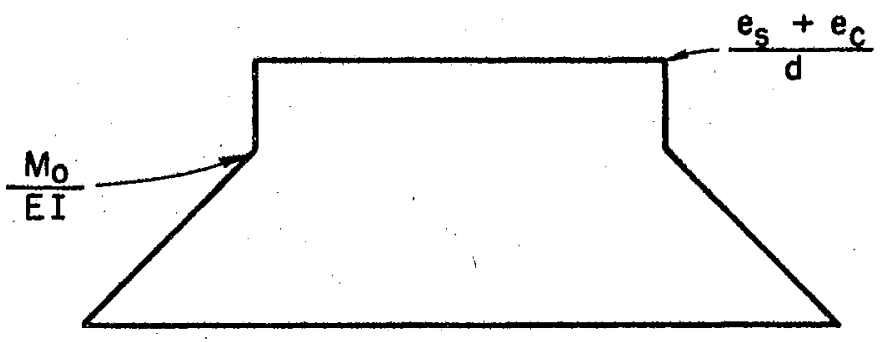

UNIT ROTATION DIAGRAM

Figure 7. Unit Rotation Diagram at UItimate Load 
where $F_{1}$ is the force remaining on the beam after the system comes to rest.

Solution of the homogeneous equation yields

$$
\begin{aligned}
s_{1,2} & =-\frac{c}{2 m_{e}} \pm \sqrt{\left(\frac{c}{2 m_{e}}\right)^{2}-\frac{k}{m_{e}}} \\
y & =A e^{s_{1} t}+B^{\prime} e^{s_{2} t},
\end{aligned}
$$

where $A$ and $B$ ' are arbitrary constants depending on the boundary conditions.

Defining the critical damping coefficient $c_{c}$ as

$$
\frac{c_{c}}{2 m_{e}}=\sqrt{\frac{k}{m_{e}}}=w_{n}
$$

a nondimensional ratio referred to as the damping factor is obtained:

$$
\varphi=\frac{c}{c_{c}} .
$$

Making this substitution into the homogeneous equation solution yields

$$
s_{1,2}=\left[-\varphi \pm \sqrt{\varphi^{2}-1}\right] w_{n} .
$$

When the damping is light $(\varphi<1.0)$ the radical is imaginary and $s$ is written as

$$
s_{1,2}=\left[-\varphi \pm i \sqrt{i-\varphi^{2}}\right] w_{n}
$$

and the solution becomes 


$$
y=e^{-\varphi_{n} t}\left(A \cos \sqrt{1-\varphi^{2}} w_{n} t+B \sin \sqrt{1-\varphi^{2}} w_{n} t\right) .
$$

The particular solution to be added to the homogeneous solution is

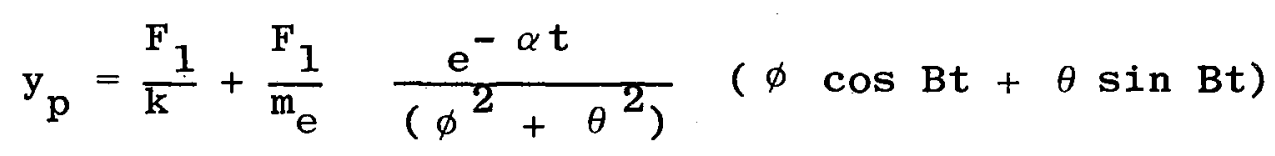

where $\phi$ is

$$
\alpha^{2}-\mathrm{B}^{2}-\frac{\alpha \mathrm{c}}{\mathrm{m}_{\mathrm{e}}}+\frac{\mathrm{k}}{\mathrm{m}_{\mathrm{e}}}
$$

and $\theta$ is

$$
-2 \alpha B+\frac{c B}{m_{e}}
$$

The complete solution now becomes

$$
\begin{aligned}
y & =e^{-\varphi w_{n} t}\left[A \cos \sqrt{1-\zeta^{2}} w_{n} t+B^{\prime} \sin \sqrt{1-\varphi^{2}} w_{n} t\right] \\
& +\frac{F_{1}}{k}+\frac{F_{1} e^{-\alpha t}}{m_{e}\left(\phi^{2}-\theta^{2}\right)} \quad(\phi \cos B t+\theta \sin B t) .
\end{aligned}
$$

The damping factor $\boldsymbol{\varphi}$ is obtained from the equation (26)

$$
\varphi=\frac{\delta}{2 \pi}=\frac{\ln \left(x_{n} / x_{n+1}\right)}{2}
$$

where the logarithmic decrement $\delta$, is defined as the natural logarithm of the ratio of any successive deflection amplitude of the deflection-time, strain-time or other response curve.

An example of calculating the theoretical dynamic load deflection curve is given in Appendix E. 


\section{CHAPTER IV}

\section{RESULTS AND DISCUSSION}

\subsection{Static Tests}

Two simply supported beams $\mathrm{S}-1$ and $\mathrm{S}-2$ were tested to failure. Both beams failed completely after an initial compression failure of the concrete. Once the concrete had failed in compression, the displacement increased at an increasing rate with a decrease in load. Complete failure occurred with the breaking of the strands. The strands in both beams broke in the same manner; one strand would break, then with an increase in deflection the remaining strands would break.

During the testing of beam $\mathrm{s}-1$, the third point loading rig slipped in its position and started to show excessive deflection after a load of $20 \mathrm{kips}$ had been applied. The load was removed and a permanent beam deflection of 0.072 inches was measured. The loading rig was repaired and the load was once again applied. The beam acted as an elastic member, with a section modulus as computed from a transformed section, during reloading up to a load equal to the original $20 \mathrm{kip}$ load. This is shown in Figures D-1 and D-2 in Appendix D. With continued loading it was found difficult to hold the load at a constant value due to the 
increased deflection of the beam. This was caused by yielding of the steel in the beam.

The experimental response curves for the beams are shown in Appendix D. An example of the theoretical static load deflection curve up to ultimate load is also given.

\subsection{Dynamic Tests}

The seven remaining beams were tested dynamically. A summary of the dynamic test data is tabulated in Table II. Pictures of the beams after loading are shown in Appendix C.

TABLE II

SUMMARY OF DYNAMIC TESTS

\begin{tabular}{ccccc}
\hline $\begin{array}{c}\text { Test } \\
\text { Beam }\end{array}$ & $\begin{array}{c}\text { Maximum } \\
\text { Dynamic } \\
\text { Load Kips }\end{array}$ & $\begin{array}{c}\text { Maximum } \\
\text { Def lection } \\
\text { inches }\end{array}$ & $\begin{array}{c}\text { Time of } \\
\text { Max. Def } 1 \\
\text { msec. }\end{array}$ & $\begin{array}{c}\text { Permanent } \\
\text { Def lection } \\
\text { inches }\end{array}$ \\
\hline D-1 & 22.7 & 1.05 & 39 & 0 \\
D-2 & 32.5 & -- & 36 & - \\
D-3 & 33.1 & 2.15 & 45 & .40 \\
D-4 & 29.9 & 1.94 & 48 & .32 \\
D-5 & 31.2 & -- & 31 & - \\
D-6 & 29.9 & 1.88 & 46 & .47 \\
D-7 & 26.6 & 1.40 & 44 & .38 \\
\hline
\end{tabular}

The response curves for the beams are shown in Appendix E. The information as shown was recorded directly on magnetic tape during the tests, then later recorded through a strip chart recorder. 
A comparison of the output of the tape system and the $16 \mathrm{~mm}$ film showed identical results. A trace of the output of the load ring gages on the film enabled this comparison to be made. The films were projected onto a screen by a time and motion study projector equipped with a frame counter and a manual hand crank used for advancing the film one frame at a time. The film was run until first movement of the oscilloscope dot was observed. The projector was stopped and the film cranked backward until frame zero was established. The film was then advanced one frame at a time for the analysis. A plot of the oscilloscope dot movement was the same as that obtained through the recording system, as expected.

Referring to Appendix $E$, it can be seen that the general patterns of the load and reaction curves are very similar for all tests. The load was applied very rapidly reaching its initial peak in 0.005 seconds. As the beam moved downward from this initial impact, the applied load was reduced as the beam accelerated from the load ring. This reduction continued until the applied load reached a minimum value, usually about 50 per cent of the initial maximum peak load. As the beam acceleration decreased, the load again increased. This cyclic loading continued in a decaying manner until the beam either came to rest supporting the load or failed.

The reaction $r i n g$ reacted in much the same manner. There occurred, in each of the tests, a time lapse before 
the reaction started to build up. This time lapse was approximately 0.0025 seconds for each of the beams. This time closely approached the time required for a shock wave to travel from the load ring to the reaction ring through the atmosphere, approximately 1100 feet per second. Before a build up of the reaction there was a very small negative value. This negative value never became as large as one half of the weight of the beam, thus the beam never lost contact with the reaction ring.

The reaction values showed a very rapid increase but did not attain maximum value until the beam had oscillated several times. The oscillations continued, in a decaying manner, until the beam came to rest or failed.

The variation of displacement compared with the applied load can be seen on the response curves, Appendix E. Beams D-2 and D-5 both failed during the testing, therefore providing very little usable information as to deflection characteristics. The general pattern of behavior is similar for the remaining beams. The first deflection peak was usually attained in 0.04 seconds after the initial application of the load. During this time, the load-time curves show that approximately five cycles were completed. Following the first deflection peak, the beams vibrated in the cyclic manner characteristic of a damped system. Upon removal of the load rings, the permanent deflection was recorded and was extremely small, in some cases less than the original camber, so that the final unloaded position of the 
beam was still above the horizontal.

As the beams were unloaded, the cracks present in the tensile zone under load completely closed. Cracks which extended as much as $71 / 2$ inches into the 10 inch depth closed so tightly that they were difficult to locate.

The applied dead load and live load moments acting on a11 beams were computed from the physical characteristics of the beams and the known loads. These applied moments were compared with the theoretical ultimate static moment.

The ultimate static moment was computed using the A.C.I. Code (27) without the capacity reduction factor $\phi$, and is:

$$
M_{u}=A_{s} f_{s u} d(1-0.59 q)
$$

where $q$ is defined as:

$$
q=p \frac{f_{s u}}{f_{c}^{\top}}
$$

The comparison between the actual and theoretical ultimate static moments is shown in Table III.

TABLE III

THEORETICAL AND ACTUAL STATIC MOMENTS

\begin{tabular}{ccc}
\hline $\begin{array}{l}\text { Test } \\
\text { Beam }\end{array}$ & $\begin{array}{c}\text { Computed U1timate } \\
\text { Moment Kip-inches }\end{array}$ & $\begin{array}{c}\text { Actual Breaking Moment } \\
\text { Kip-inches }\end{array}$ \\
\hline \multirow{2}{*}{ S-2 } & 364.0 & 370.0 \\
S-1 & 363.1 & 368.6 \\
\hline
\end{tabular}

The ratio of the applied dynamic moment to the 
theoretical ultimate static moment is shown in Table IV.

TABLE IV

RATIO OF APPLIED DYNAMIC MOMENT TO

THEORETICAL STATIC MOMENT

\begin{tabular}{lccl}
\hline $\begin{array}{c}\text { Test } \\
\text { Beam }\end{array}$ & $\begin{array}{c}\text { Applied Dynamic Moment } \\
\text { Kip-inches }\end{array}$ & $\begin{array}{c}\mathrm{M}_{\mathrm{d}} \\
\bar{M}_{\mathrm{s}}\end{array}$ & \multicolumn{1}{c}{ Remarks } \\
\hline $\mathrm{D}-1$ & 363.2 & 1.00 & no failure \\
D-2 & 520.0 & 1.43 & complete fallure \\
D-3 & 529.6 & 1.46 & verge of fallure \\
D-4 & 478.4 & 1.31 & partial failure \\
D-5 & 499.2 & 1.37 & complete fallure \\
D-6 & 478.4 & 1.31 & verge of failure \\
D-7 & 425.6 & 1.17 & no failure \\
\hline
\end{tabular}

One of the main objects of this study was to try to find the critical ratio of dynamic ultimate moment to static ultimate moment. It was extremely difficult to determine the point at which the impact loading brought the beam to the verge of failure. Of the seven dynamic tests, three tests appeared to bring the beam to the verge of failure or partial failure. For purposes of this study, partial failure will be defined as cracks forming in the horizontal plane at the boundary of the compression zone as a prelude to the concrete in that area breaking away. The verge of failure is defined the same as partial failure but with the addition of chipping of the concrete as if the breaking away was imminent. Beams D-3 and D-6 both were 
classified as being on the verge of failure; Beam D-4 was classified as partial failure. Beam D-l did not form horizontal cracks and Beam D-7 showed the slightest beginning of these cracks.

From the ratio of dynamic ultimate moment to the static ultimate moment of Beams D-3, D-4, and D-6, it can be seen that an average of 35 per cent greater dynamic moment is required to cause failure of the member, see Figure C-3. The number of tests was not sufficient to provide conclusive proof of this 35 per cent figure, but would lead one to believe that this would be in the upper range that could be expected. This is an area in which further investigation should be done. 
CHAPTER V

FINDINGS AND CONCLUSIONS

\subsection{Summary and Conclusions}

This test program shows that pretensioned prestressed members have excellent qualities for this type of loading. The recovery characteristics are exceptional; the capacity to carry the dynamic effect appears to be about one third greater than for static loading; and the members are much smaller and lighter than reinforced concrete members.

1. The time lapse between load and reaction build up was small and could be predicted by the velocity of the shock wave moving through the atmosphere.

2. Maximum load was attained during the first cycle, whereas maximum reaction was not reached until after several cycles.

3. Maximum deflection occurred after several cycles of loading had occurred and at approximately the same time that maximum reaction occurred.

4. The reaction and displacement curves were very similar in their nature.

5. The recovery of the members was excellent. Cracks, which had extended 75 per cent into 
the depth of the member, closed upon removal of the load, so that they were difficult to locate.

6. The permanent deflection was extremely small even when loaded as much as 30 per cent over the ultimate static moment.

7. The ultimate static moment, as computed by the A.C.I. Code without the capacity reduction factor, was the same as the actual static moment when the value of $f_{s u}$ was determined by tension tests in the laboratory.

8. The ratio of ultimate dynamic moment to ultimate static moment had an upper range of about 135 per cent. Thus, it appears that it would be possible to compute the ultimate static moment and increase this by about one third to predict the ultimate dynamic moment.

9. The theoretical calculation of the static deflection curve closely approximates the experimental deflection curve. The unit rotation diagram used after initial yield of the steel predicted very closely the maximum deflection.

10. The assumed single degree of freedom system for dynamic loading can be used to predict the response of the member after the section has cracked. 


\subsection{Extension of Work}

This work should be extended to include the testing of more members in order to confirm the one third figure as reasonable for prediction of the dynamic ultimate moment.

Additional work would include the testing of members with various sizes and percentages of steel.

A major testing program might go so far as the testing of a rigid frame to find the effect of the impulsive load on columns and connections.

The application of loads at various loading frequencies should be investigated.

Since no permanent effect could be observed with the application of a single dynamic load equal to the static load, a program of repeated dynamic loadings at the static load should be investigated. 


\section{SELECTED BIBLIOGRAPHY}

1. Takahashi, S. K., "Static and Dynamic Loading of Pretensioned Concrete Beams," Naval Civil Engineering Laboratory (NCEL) Technical Report R-192. Port Hueneme, California, June 1962.

2. Taylor, G. I., "Testing of Materials at High Rates of Loading," Journal, Inst. Civil Eng., Vol. 26, pp. 486-519 (1946).

3. Clark, D. S., "The Behaviour of Metals Under Dynamic Loading," Metal Progress, Vol. 64, No. 5, pp. 6773 (1953).

4. Rawson, Robert, "Memoir of Eaton Hodgkinson," Annual Report, Smithsonian Institution, 1868, pp. 203230.

5. Mann, H. C., "High-Velocity Tension-Impact Tests," Proceedings, Am. Soc. Testing Materials, Vol. 36, Part II, pp. 85-109 (1936).

6. Slater, W. A., Smith, G. A., "Tension, Bend and Impact Tests on Reinforcement Bars," Proceedings, Am. Soc. Testing Materials, Vo1. 29, Part II, pp. 183-203 (1929).

7. Mann, H. C., "High-Velocity Tension-Impact Tests," Proceedings, Am. Soc. Testing Materials, Vol. 36, Part II, pp. 85-109 (1936).

8. Fehr, R. O., Parker, E. R., DeMichae1, D. J., "Measurement of Dynamic Stress and Strain in Tensile Test Specimens," Journal of Applied Mechanics, Trans., ASME, Vol. 66, pp. A.65-A.71 (1944).

9. Fink, K., "Ueber Schlagversuche an Flusstahlproben mit allgemeinen Folgerungen für Untersuchungen an stossartig beanspruchten Festen Stoffen," Schweizer Archiv., Vol. 15, pp. 193-214 (1949).

10. Vivian, A. C., "Tension Impact Testing," Struct. Engineering, Vo1. 30, pp. 121-128 (1952).

11. Penzien, J., Hansen, R. J., "Static and Dynamic Elastic Behavior of Reinforced Concrete Beams," 
Journal, Am. Concrete Inst., Vol. 25, pp. 545-567 (1954).

12. Mylrea, T. D., "Effects of Impact on Reinforced Concrete Beams," Proceedings, Highway Research

Board; Nat'l. Research Council, Vol. 18, pp. 130139 (1938) and Journal, Am. Concrete Inst., Vol. 11 , pp. 581-596 (1940).

13. Speth, 0., "Bombenwirkungen gegen Stahlbeton Und Ermittlung von Schvtzdicken," Bauingenieur, Vol. 23, pp. 339-353 (1942).

14. Penzien, J., Hansen, R. J., "Static and Dynamic Elastic Behaviour of Reinforced Concrete Beams," Journal, Am. Concrete Inst., Vol. 25, pp. 545-567 (1954).

15. Mavis, F. T., Richards, F. A., "Impulse Testing of Concrete Beams," Journal, Am. Concrete Inst., Vol. 27, pp. 93-102 (1955).

16. Mavis, F. T., Greaves, M. J., "Destructive Impulse Loading of Reinforced Concrete Beams," Journal, Am. Concrete Inst., Vol. 54, pp. 233-252 (1957).

17. Stewart, J. J., "Effects of Impulsive Loads Upon Reinforced Concrete Beams," Thesis (unpublished), Carnegie Institute of Technology, 1957.

18. Magne1, G., Prestressed Concrete. McGraw-Hill Book Co., 3rd. Ed. 1954, pp. 168-170.

19. A Preliminary Report on the Impact Resistance of Prestressed Concrete Flexural Members, British Building Research station, Garston; Watford, Herts, England, 1951.

20. Bate, S. C. C., "Strength of Concrete Members Under Dynamic Loading," Symposium on the Strength of Concrete structures (Session D, paper No. 2) Building Research Station, Garston, Watford, Herts, England.

21. Allgood, J.A., Miyamato, H. T., "Blast Load Tests on Post Tensioned Concrete Beams," Naval Civil Engineering Laboratory (NCEL) Tech. Report R-116, Port Hueneme, California, May 1961.

22. Allgood, J. A., Shaw, W. A., "An Atomic Blast Simulator," SESA Proceedings, Vol. 17, No. 1 (1959).

23. Wadlin, G. K., Stewart, J. J., "Comparison of Prestressed Concrete Beams and Conventionally 
Reinforced Concrete Beams Under Impulsive Loading," Journal, Am. Concrete Inst., Vol. 50, No. 4, October 1961, pp. 407-421.

24. Hognestad, E., Hanson, N. W., and McHenry, D., "Concrete Stress Distribution in Ultimate Strength Design," Proceedings, Journal of Am. Concrete Inst., VoI. 52, December 1955, pp. 455479 .

25. Swihart, G., Allgood, J., and Shaw, W., "Elastic Resistance of Reinforced Concrete Beams," Journa 1, A.S.C.E., Vol. 85, ST 1, Part 1, Jan. 1959, pp. 43-63.

26. Timoshenko, S., and Young, D., Vibration Problems in Engineering. D. VanNostrand Company, Inc., New York, 1956.

27. Building Code Requirements for Reinforced Concrete, Manual 318-63, American Concrete Institute. 
APPENDIX A

WIRING DIAGRAMS OF INSTRUMENTATION 
SHIELD ON INPUT CONNECTED

TO LOW OF OUTPUT

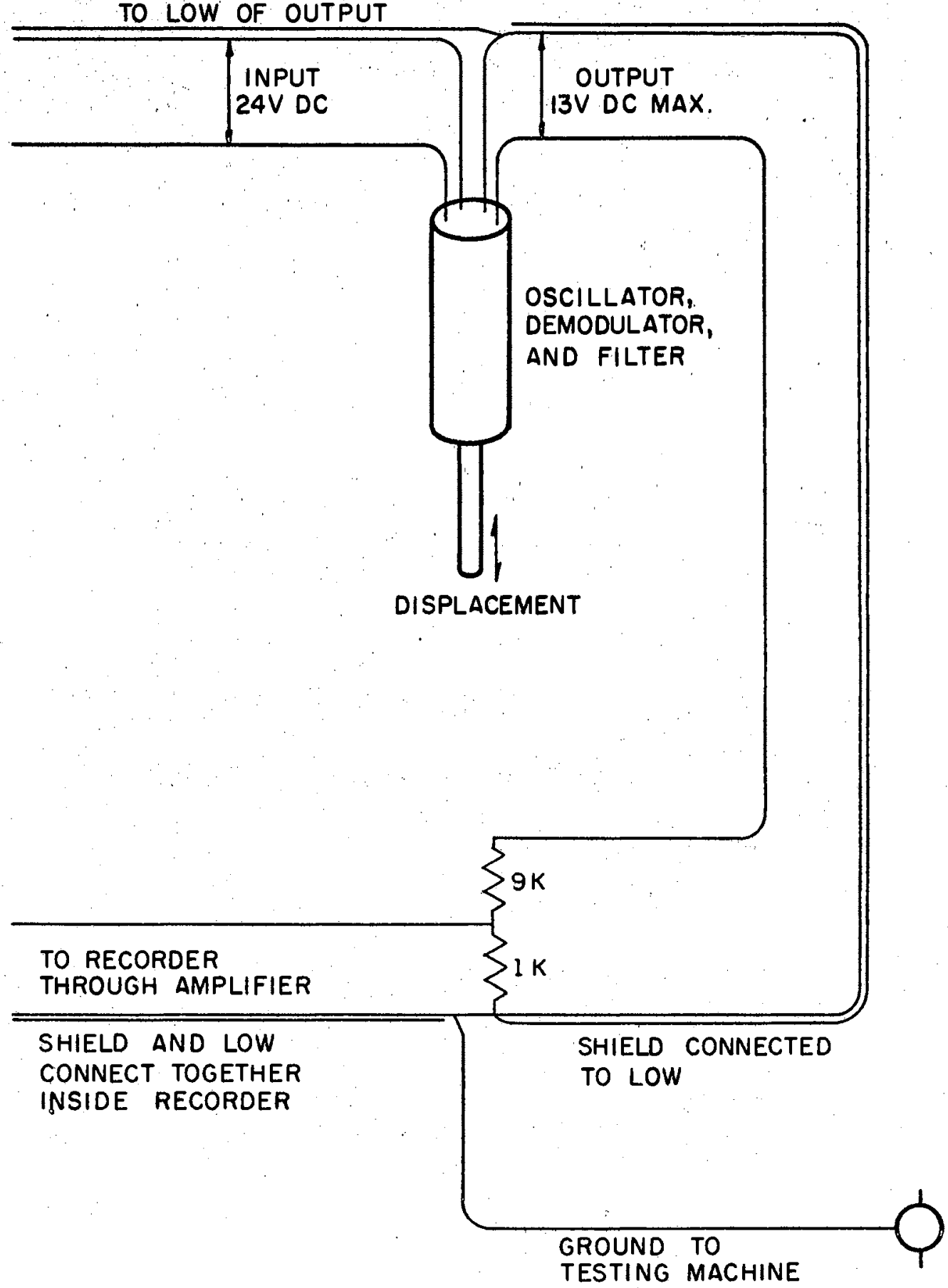

Figure A-1. Circuit for Displacement Transducer 


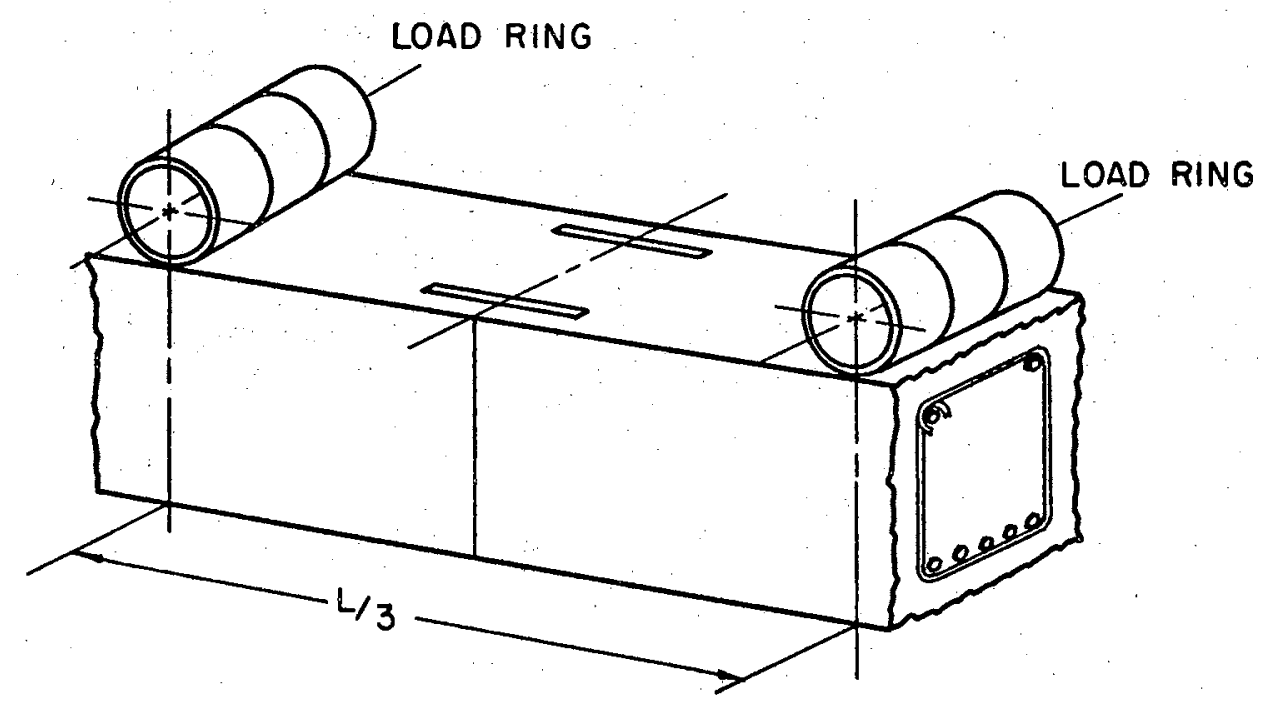

LOCATION OF ACTIVE GAGES
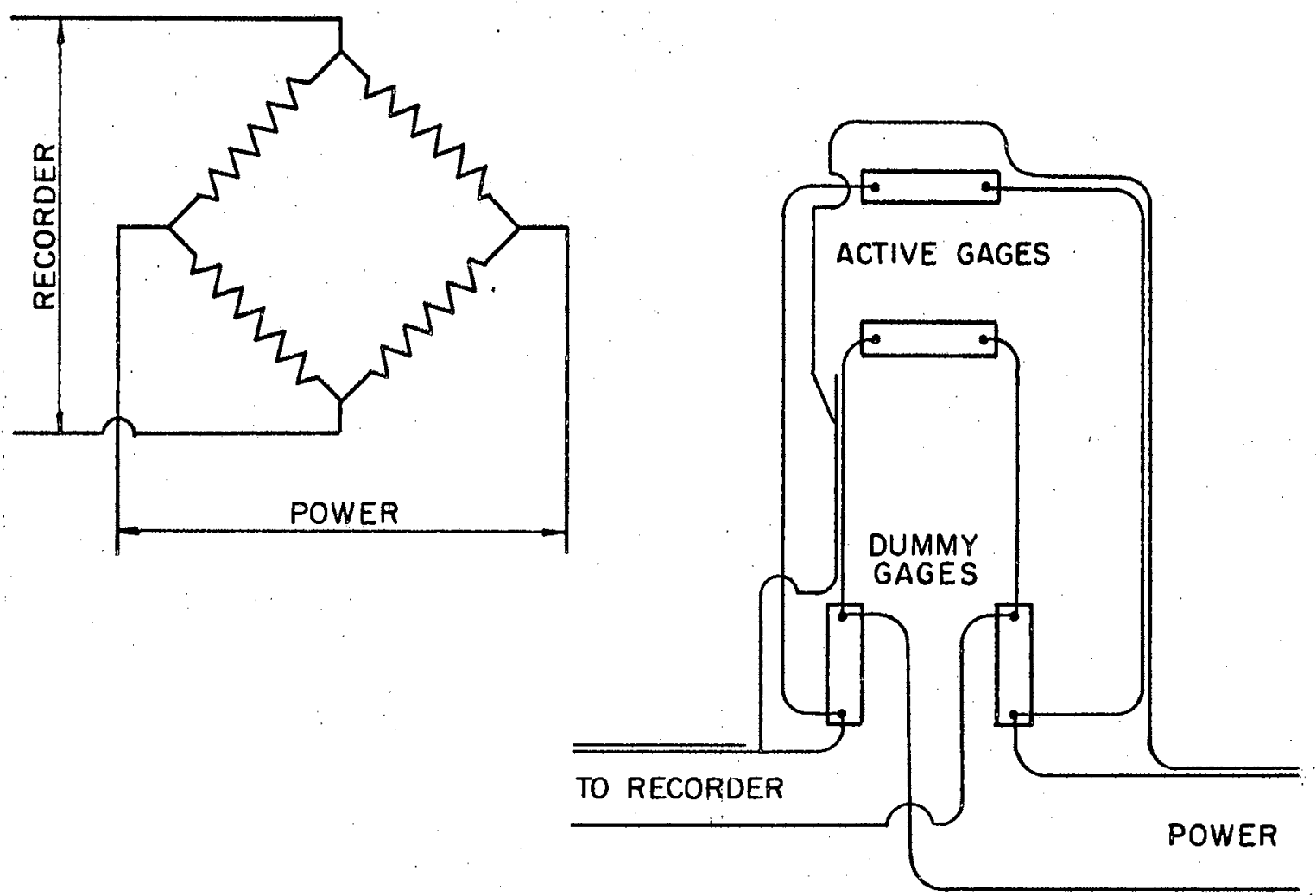

Figure A-2。 Circuit for Bridge of Gages on Member 

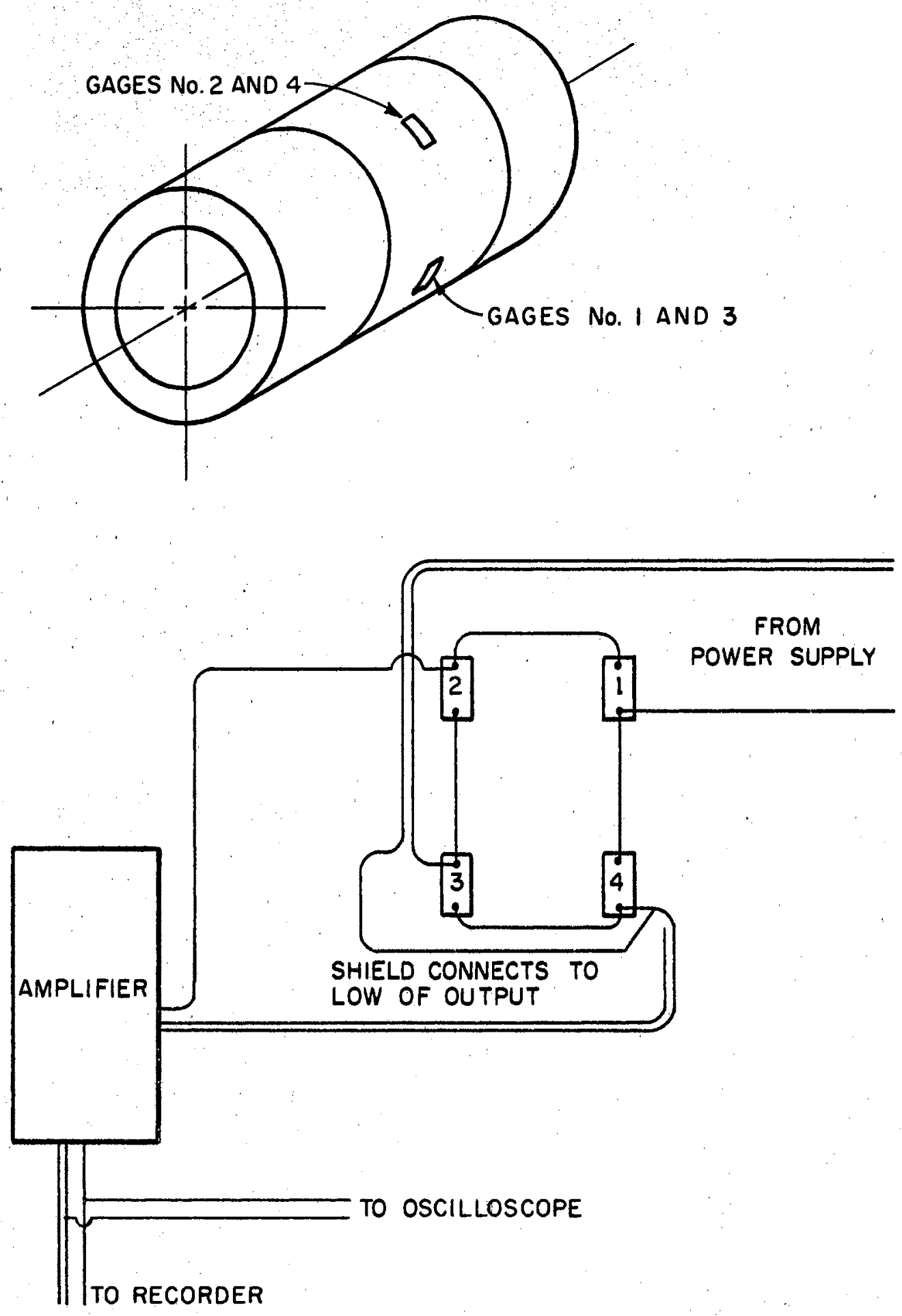

Figure A-3. Circuit for Load Ring 


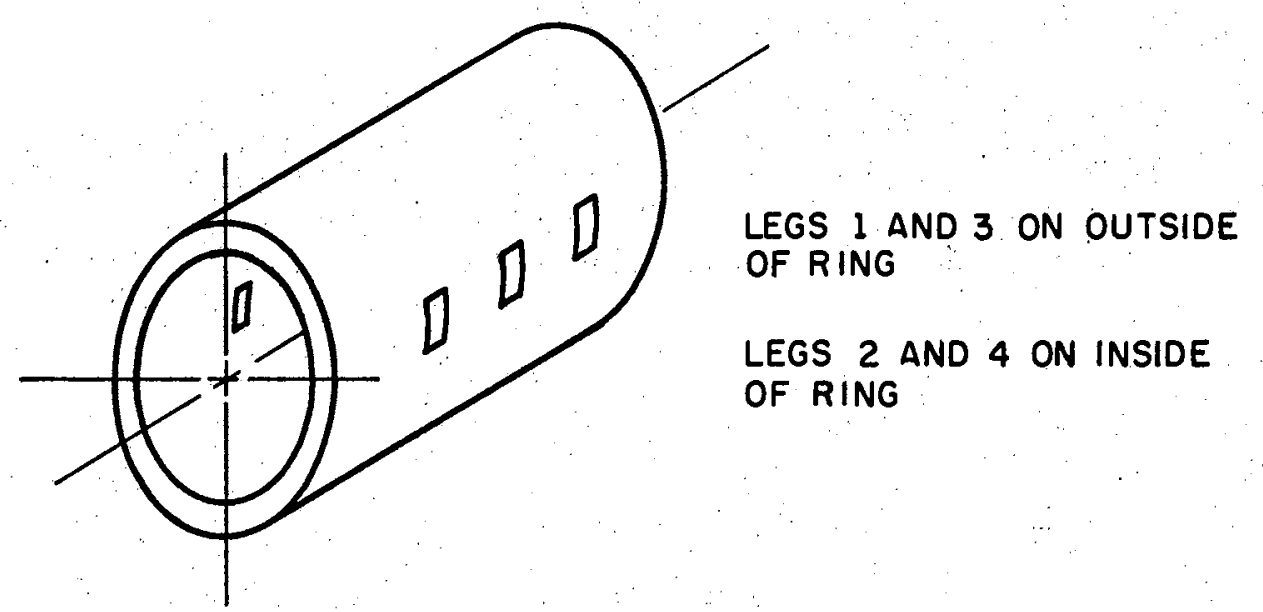

3 GAGES, 120 OHMS EACH, CONNECTED IN SERIES TO FORM EACH LEG OF BRIDGE

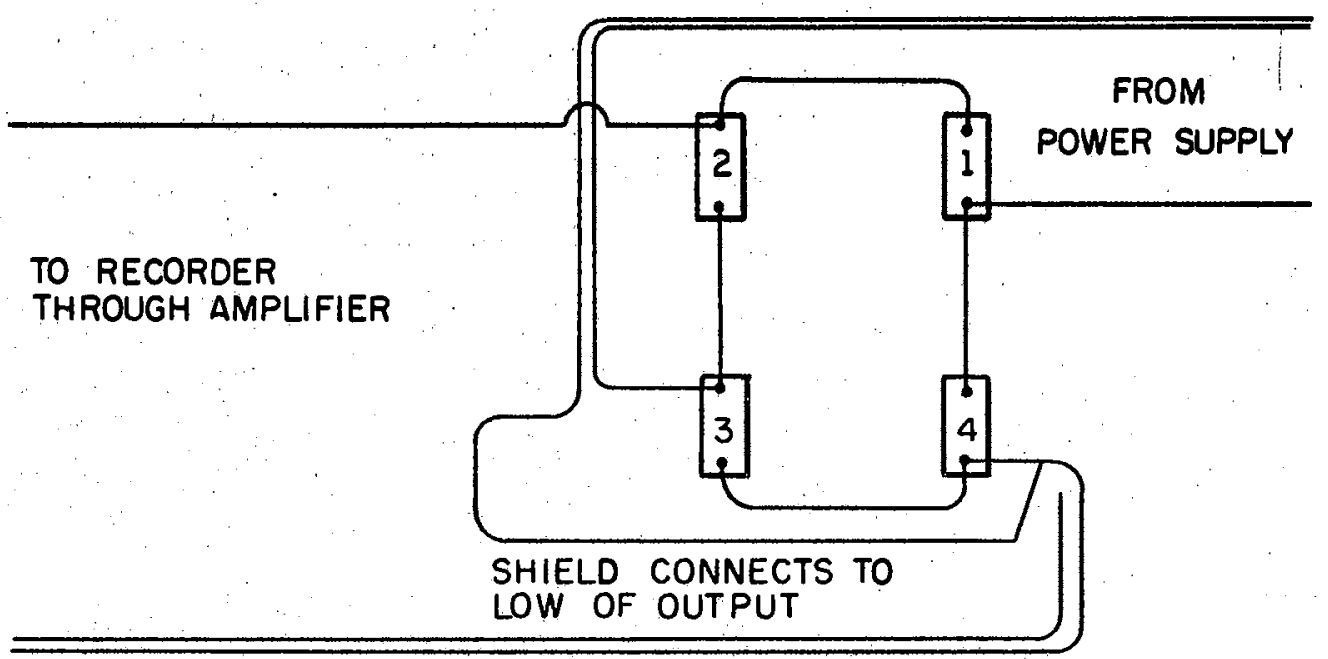

Figure A-4. Circuit for Reaction Ring 


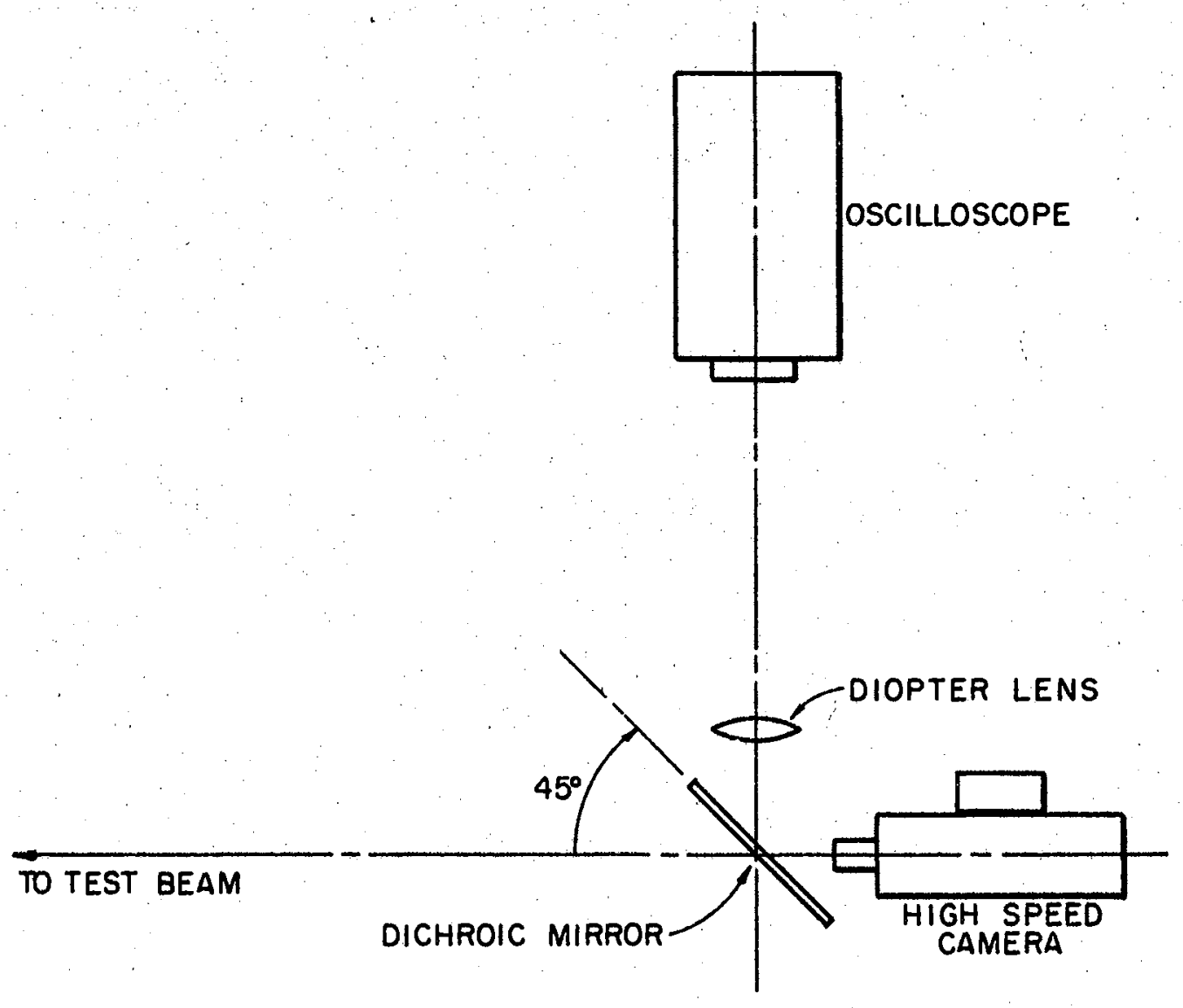

Figure A-5. Plan View of Camera Instrumentation 
APPENDIX B

PHOTOS OF TEST SETUP 


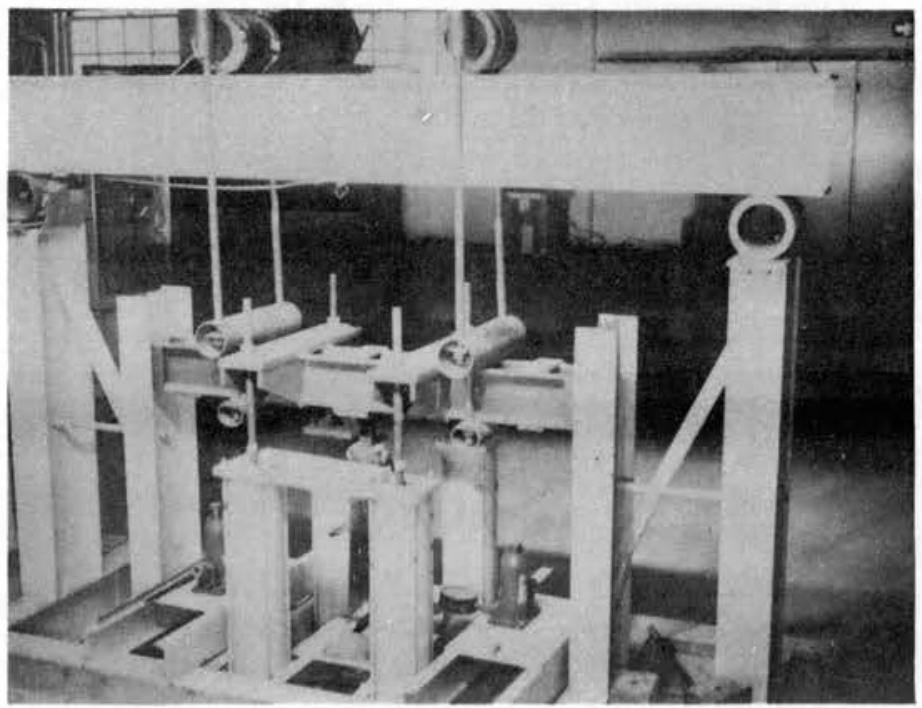

Figure B-1. Dynamic Testing Machine

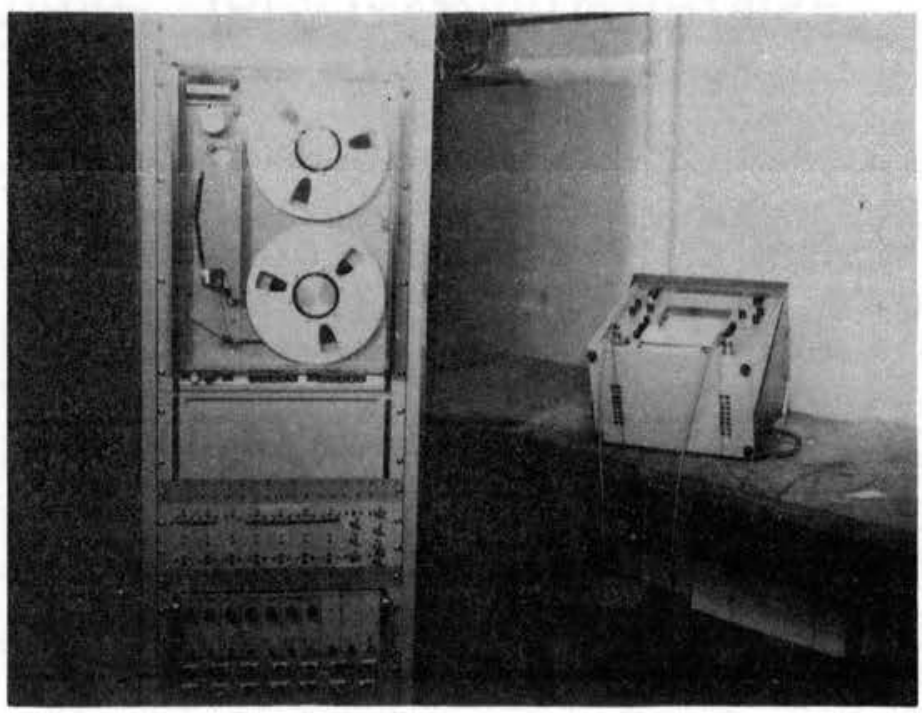

Figure B-2. Recorders 


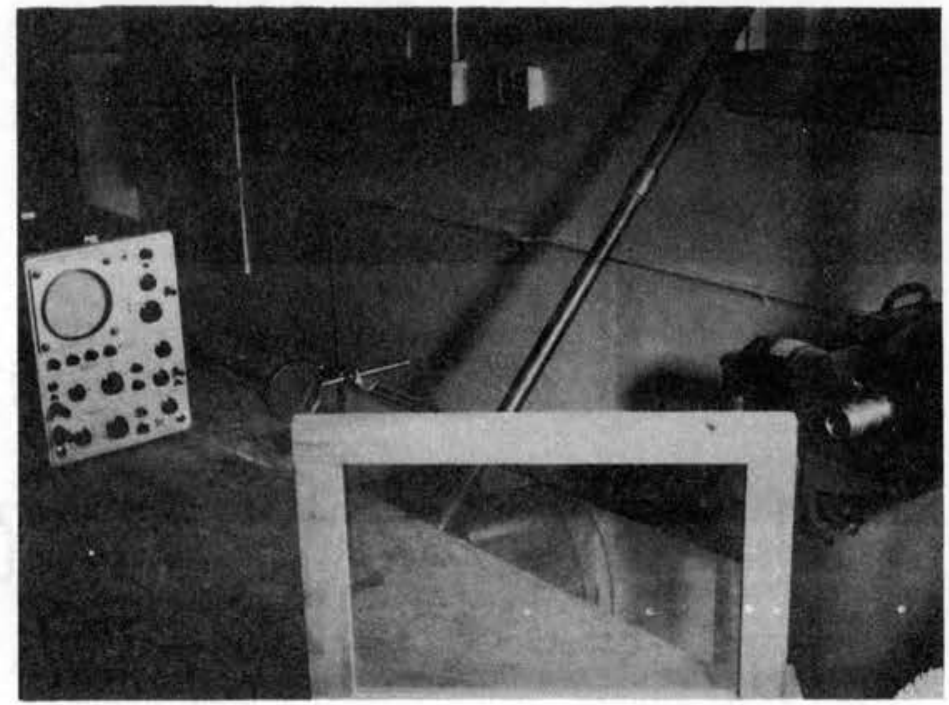

Figure B-3. Camera Instrumentation 
APPENDIX $C$

PHOTOS OF TEST MEMBERS 


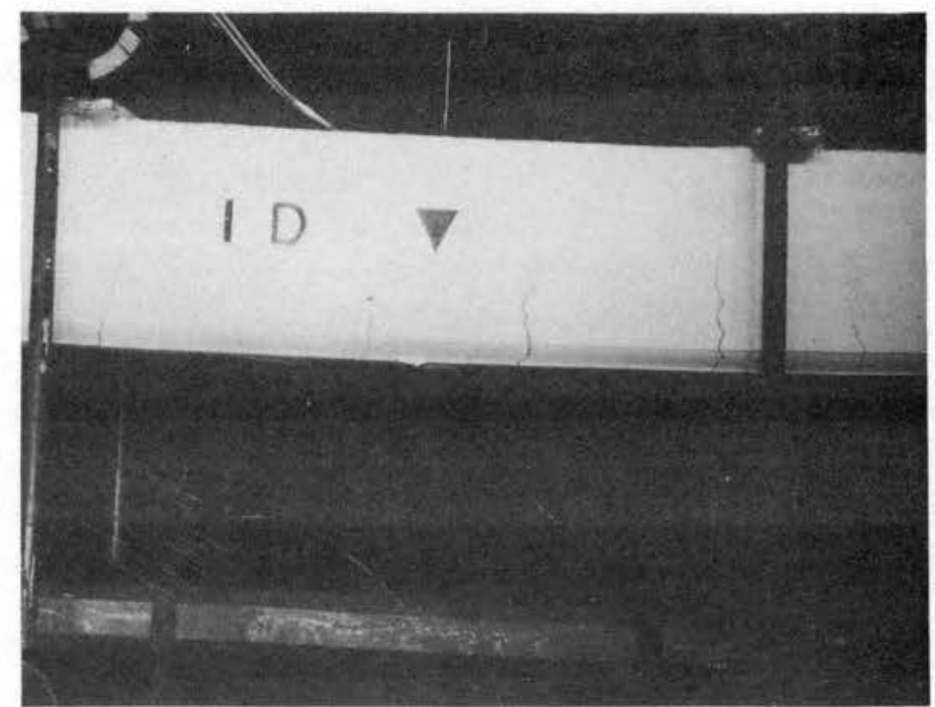

Figure C-1. Beam D-1 After Dynamic Load of $22.9 \mathrm{Kips}$

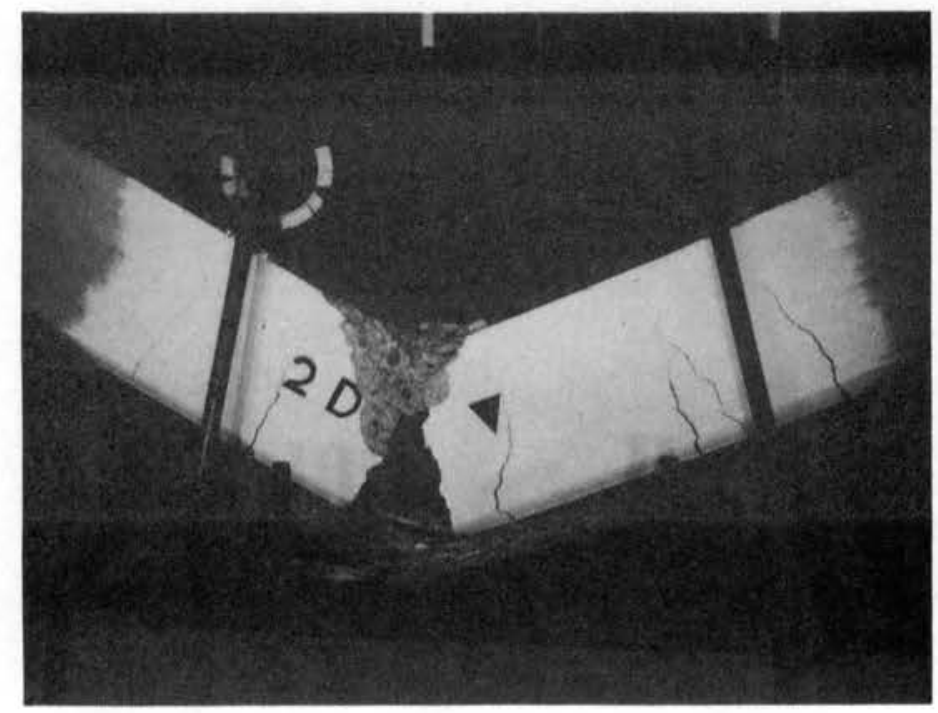

Figure C-2. Beam D-2 After Dynamic Load of $32.5 \mathrm{Kips}$ 


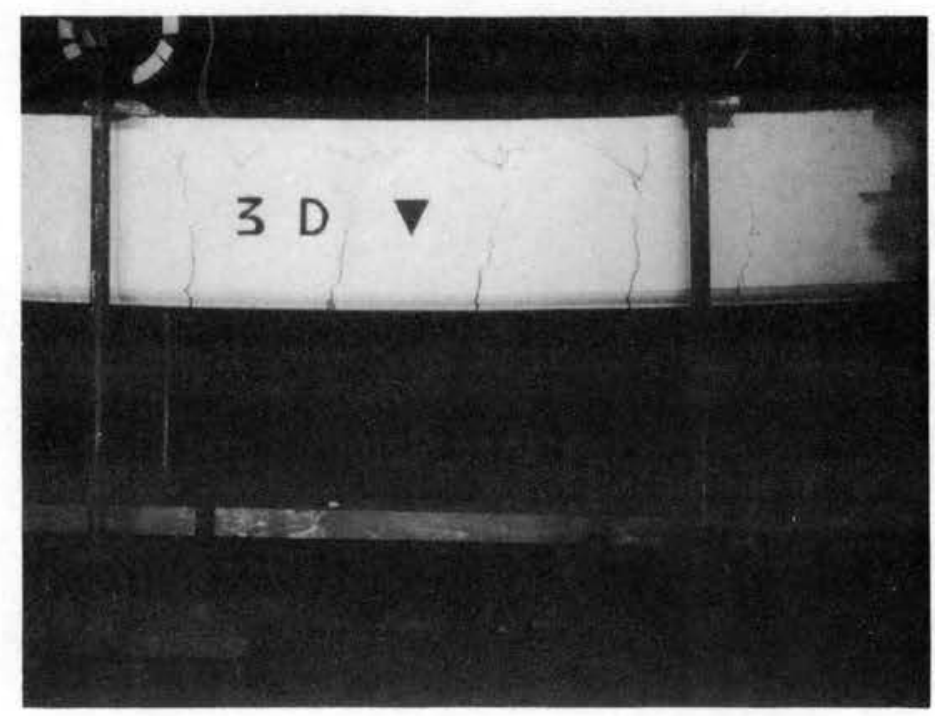

Figure C-3. Beam D-3 After Dynamic Load of $33.1 \mathrm{Kips}$

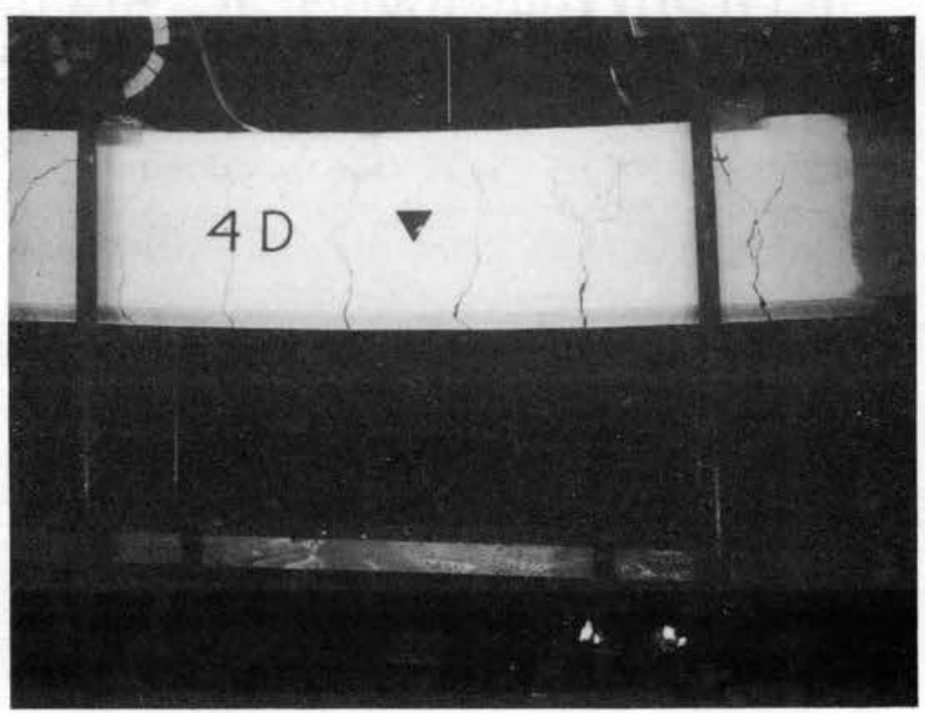

Figure C-4. Beam D-4 After Dynamic Load of $29.9 \mathrm{Kips}$ 


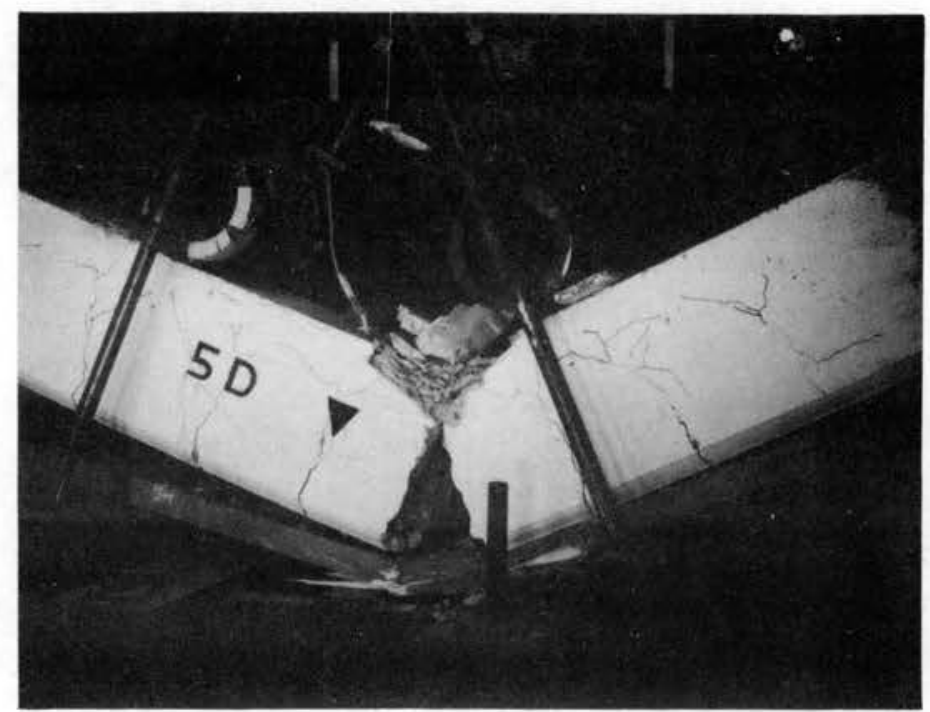

Figure C-5. Beam D-5 After Dynamic Load of $31.2 \mathrm{Kips}$

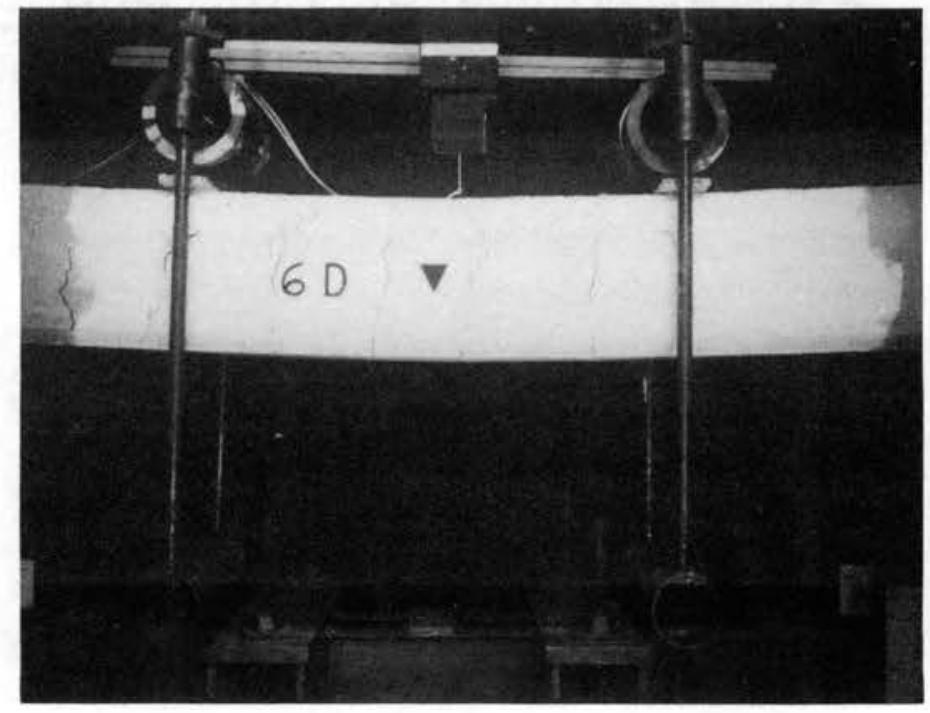

Figure C-6. Beam D-6 After Dynamic Load of $29.9 \mathrm{Kips}$ 


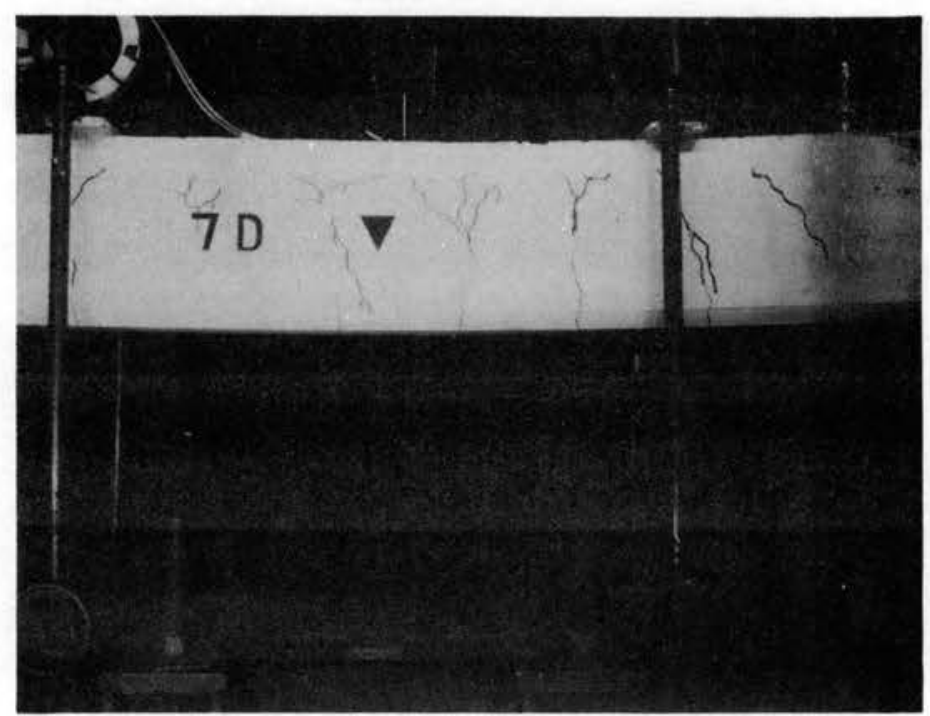

Figure C-7. Beam D-7 After Dynamic Load of $26.6 \mathrm{Kips}$

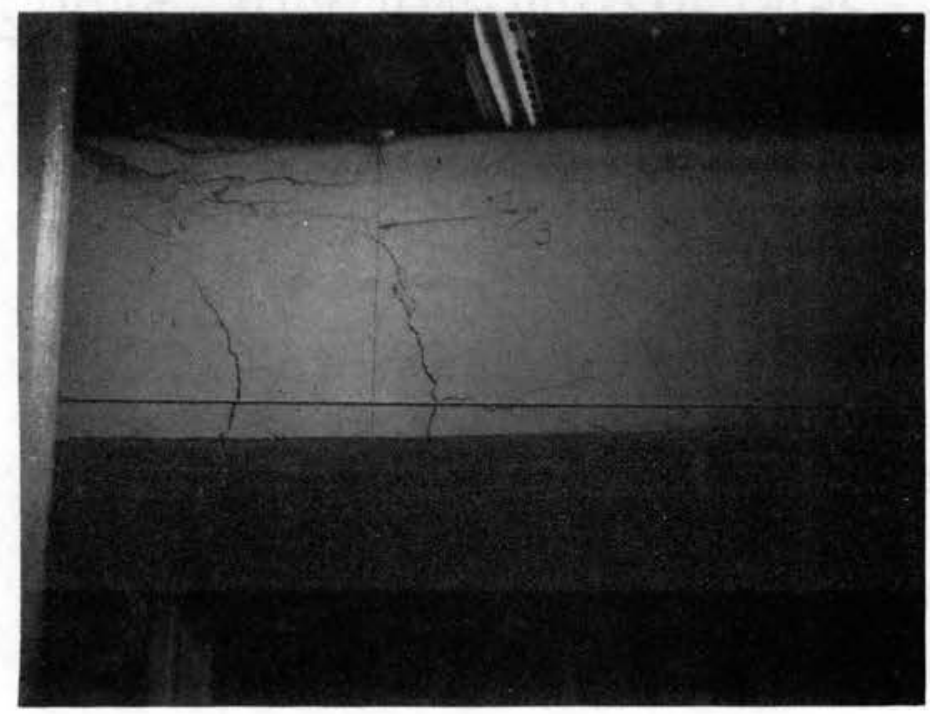

Figure C-8. Beam S-1 After Static Load of 23 Kips 
APPENDIX D

STATIC TEST RESPONSE CURVES

61 


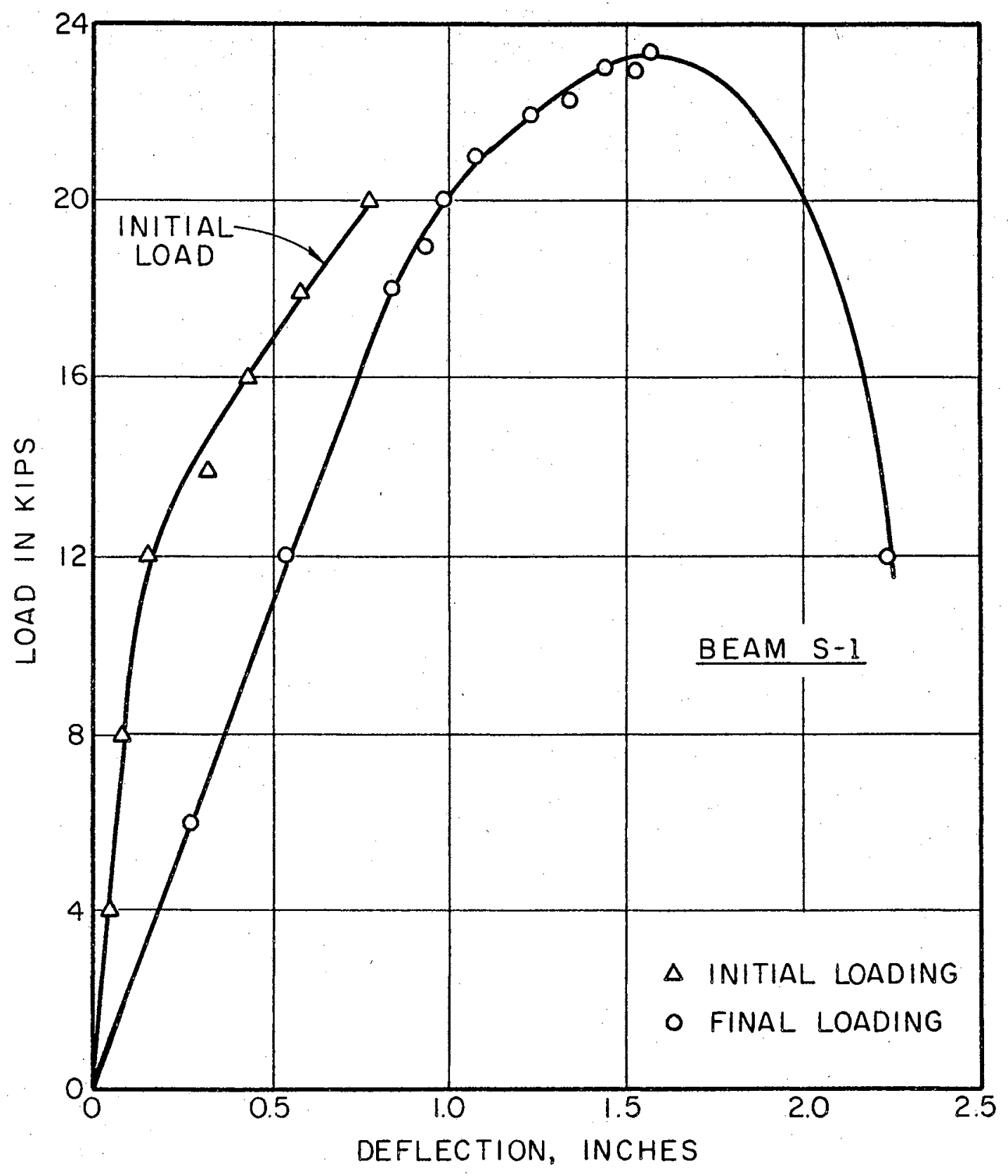

Figure D-1. Load-Deflection Curve Beam S-1 


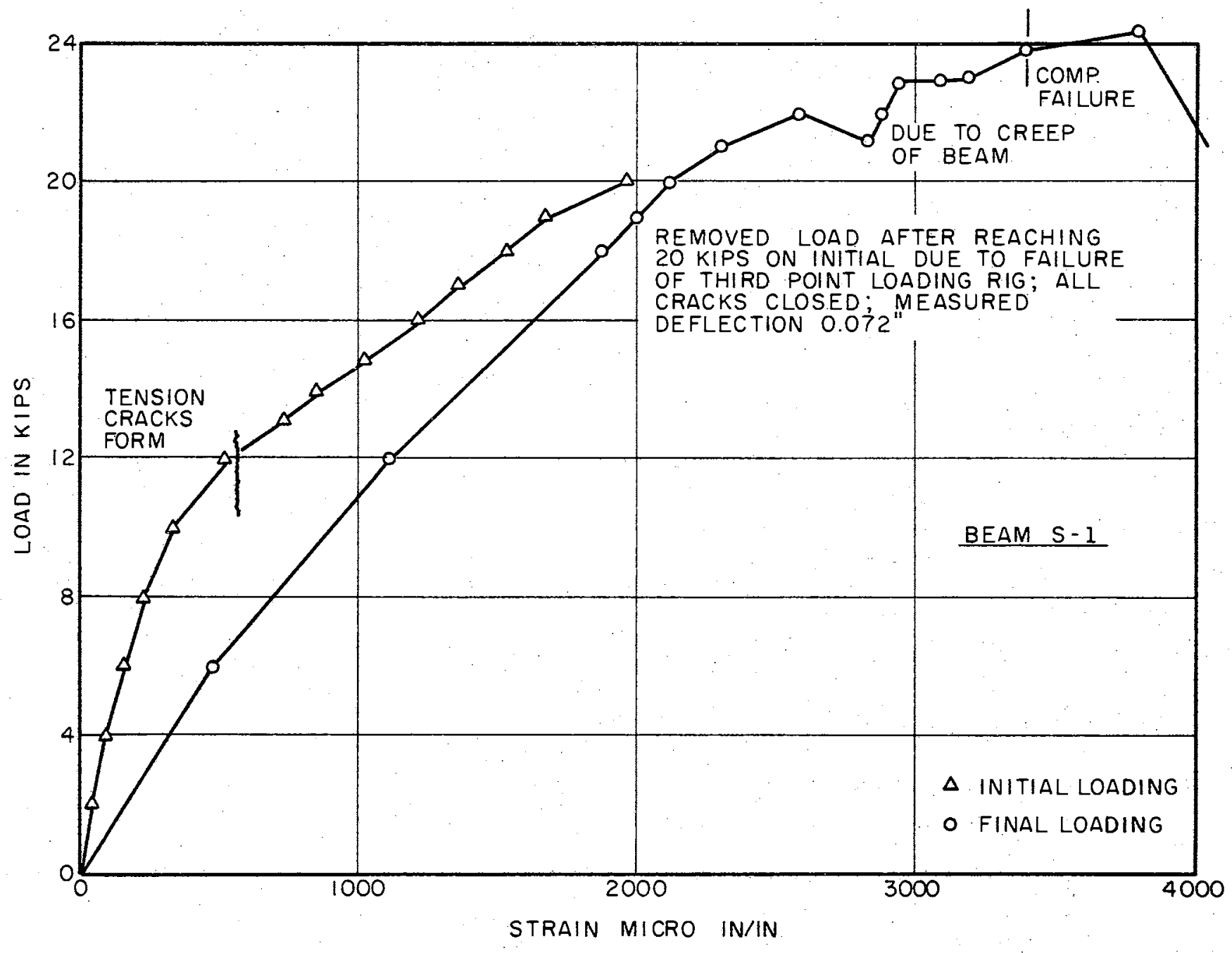

Figure D-2. Load-Strain Curve Beam S-1 


\section{APPLICATION OF THEORY FOR STATIC LOADS}

To compare the theoretical computation with experimental values, Beam $\mathrm{S}-2$ was chosen. The properties of this beam are:

$$
\begin{aligned}
& \mathrm{h}=10 \text { inches } \\
& \mathrm{A}_{\mathrm{sS}}=0.178 \mathrm{in}^{2} \\
& \mathrm{~b}=8 \text { inches } \\
& A_{S}^{:}=0.22 \mathrm{in}^{2} \\
& I=96 \text { inches } \\
& \mathrm{E}_{\mathrm{S}}=28 \times 10^{3} \mathrm{ksi} \\
& \mathrm{d}=8 \text { inches } \\
& E_{c}=4.5 \times 10^{3} \mathrm{ksi} \\
& d^{9}=2 \text { inches } \\
& \mathrm{E}_{\mathrm{S}}^{\mathrm{q}}=2.5 \times 10^{3} \mathrm{ksi} \\
& I_{x x}=667 \text { in }^{4} \begin{array}{l}
\text { uncracked } \\
\text { section }
\end{array} \\
& \mathrm{f}_{\mathrm{si}}=141.6 \mathrm{ksi} \\
& \mathrm{n}=\frac{\mathrm{E}_{\mathrm{s}}}{\mathrm{E}_{\mathrm{c}}}=6.22 \\
& \mathrm{f}_{\mathrm{yp}}=250 \mathrm{ksi} \\
& \mathrm{f}_{\mathrm{u}}=276.7 \mathrm{ksi} \\
& f_{y}=40 \mathrm{ksi} \\
& f_{\mathrm{c}}^{\prime}=5.88 \mathrm{ksi}
\end{aligned}
$$

Ultimate strain:

$$
\mathrm{e}_{\mathrm{u}}=0.004-\frac{\mathrm{f}_{\mathrm{c}}^{\mathrm{q}}}{6.5 \times 10^{3}}=.0031 \mathrm{in} / \mathrm{in} .
$$

Dead load weight $83 \mathrm{lb} / \mathrm{ft}$.

$$
\begin{aligned}
\mathrm{k}_{3} & =\frac{3.9+0.35(5.88)}{3+.82(5.88)-\left(\frac{5.88}{26}\right)^{2}}=.7667 \\
\mathrm{f}_{\mathrm{c}}^{\prime \prime} & =\mathrm{k}_{3} \mathrm{f}_{\mathrm{c}}^{\prime}=4.51 \mathrm{ksi} \\
0.85 \mathrm{f}_{\mathrm{c}}^{\prime \prime} & =3.83 \mathrm{ksi} \\
\mathrm{e}_{\mathrm{o}} & =\frac{2 f_{\mathrm{c}}^{\prime \prime}}{\mathrm{E}_{\mathrm{c}}}=.00201 \mathrm{in} / \mathrm{in}
\end{aligned}
$$


Cracking load is the load which causes the concrete to crack initially due to bending forces

$$
f_{t}^{\prime}=7.5 \sqrt{f_{c}^{\prime}}=7.5 \sqrt{5880}=575 \mathrm{psi}
$$

The initial prestress compression values are 0 at the top and $833 \mathrm{psi}$ at the bottom of the beam. The cracking moment is:

$$
M_{c r}=(.883+.575) 133.4=194.5 \mathrm{kip} \text { in. }
$$

Dead load moment:

$$
M_{d L}=\frac{W_{d l^{L}}{ }^{2}}{8}=8 \mathrm{kip} \text { in. }
$$

Net cracking moment: $M_{n}=186.5 \mathrm{kip}$ in

Cracking load: $\mathrm{P}_{\mathrm{cr}}=\frac{3 \mathrm{M}_{\mathrm{n}}}{\mathrm{L}}=5.83 \mathrm{kips}$

Cracking strain: $e_{c r}=\frac{M_{c r}}{E_{c} S}=.000324$ in $/$ in

Deflection at cracking load:

$$
\mathrm{Y}_{\mathrm{cr}}=\frac{23 \mathrm{PL}^{3}}{648 \mathrm{E}_{\mathrm{c}} \mathrm{I}}=.061 \text { inches }
$$

The additional deflection in the post cracking range is computed at four different concrete strains making use again of Reference 25. At the first point let $e_{c}=.0010$ in/in, which is less than $e_{0}$, and

$$
f_{c}=f_{c}^{\prime \prime}\left[2 \frac{e_{c}}{e_{o}}-\left(\frac{e_{c}}{e_{o}}\right)^{2}\right]
$$




$$
\begin{aligned}
& f_{c}=4.51\left[2\left(\frac{1}{2}\right)-\left(\frac{1}{2}\right)^{2}\right]=3.38 \mathrm{ksi} \\
& m=\frac{1}{3(1)}[1(2 \times 4.51+3.38)-3.38(2.0)] \\
& =1.88 \mathrm{ksi} \\
& \mathrm{T}=25.24+4.984\left(\frac{8-\mathrm{a}}{\mathrm{a}}\right) \\
& C_{s}=-6.16\left(\frac{a-2}{a}\right) \\
& C_{c}=-m b a=-15.04 a \\
& \mathrm{~T}+\mathrm{C}_{\mathrm{s}}+\mathrm{C}_{\mathrm{c}}=0 \\
& a=2.387 \text { in } \\
& \mathrm{T}=36.90 \mathrm{kips} \\
& \mathrm{C}_{\mathrm{s}}=-1.00 \mathrm{kips} \\
& \mathrm{C}_{\mathrm{c}}=-35.90 \mathrm{kips} \\
& \mathrm{k}_{2} \mathrm{a}=.828 \\
& M_{1}=C_{c}\left(d-k_{2} a\right)+\left(d-d^{\prime}\right) \\
& =35.90(7.17)+1.00(6)=263.47 \mathrm{kip} \text { in } \\
& \mathrm{P}_{1}=\frac{3 \mathrm{M}_{1}}{\mathrm{~L}}=8.23 \mathrm{kip}
\end{aligned}
$$

Increase in moment after cracking:

$$
\begin{aligned}
M_{n p l} & =263.47-194.51=68.96 \mathrm{kip} \mathrm{in} \\
I & =\frac{\mathrm{ba}^{3}}{3}+\mathrm{nA}_{\mathrm{SS}}(\mathrm{d}-\mathrm{a})^{2}=71.15 \mathrm{in}^{4}
\end{aligned}
$$




$$
\mathrm{Y}_{\mathrm{pcl}}=\frac{.10647 \mathrm{M}_{\mathrm{n}} \mathrm{L}^{2}}{\mathrm{EI}}=.21 \mathrm{in}
$$

Total deflection: $\mathrm{Y}_{1}=.06+.21=.27$ inch.

Total load on span: $2 \mathrm{P}_{1}=16.46 \mathrm{kips}$

At point two in the post cracking range let

$$
\begin{array}{rl}
\mathrm{e}_{\mathrm{c}} & =.0015 \\
\mathrm{f}_{\mathrm{c}} & =4.23 \mathrm{ksi} \\
\mathrm{m} & =2.54 \mathrm{ksi} \\
\mathrm{T} & =45.13 \mathrm{kips} \quad \mathrm{f}_{\mathrm{ss}}=\frac{\mathrm{T}}{\mathrm{A}_{\mathrm{ss}}}=253 \mathrm{ksi} \approx \mathrm{f}_{\mathrm{yp}} \\
\mathrm{C}_{\mathrm{s}} & =-.76 \mathrm{kips} \\
\mathrm{C}_{\mathrm{c}} & =-44.37 \mathrm{kips} \\
\mathrm{k}_{2}^{\mathrm{a}} & =.77 \\
\mathrm{M}_{2} & =325.35 \mathrm{kip} \mathrm{in} \\
\mathrm{p}_{2} & =10.17 \mathrm{kips} \\
\mathrm{Mp}_{\mathrm{np} 2} & =325.35-263.47=61.88 \mathrm{kip} \mathrm{in} \\
\mathrm{T}_{\mathrm{ta}} & 10 \mathrm{id}=20.34 \mathrm{kips}
\end{array}
$$$$
\text { Total deflection } \mathrm{Y}=.27+.21=.48 \mathrm{in}
$$

Initial yielding is taken at this load and deflection. 
For the third point in the post cracking range the concrete strain is taken as $e_{c}=.002 \mathrm{in} / \mathrm{in}$. Since the steel has yielded, $T$ must be calculated using the equation in the plastic range.

$$
\begin{array}{rlr}
\mathrm{a} & =2.015 \text { inches } & \\
\mathrm{T} & =48.61 \mathrm{kips} & \mathrm{M}_{3}=353.8 \mathrm{kip} \text { in } \\
\mathrm{C}_{\mathrm{S}}=-.09 \mathrm{kips} & \mathrm{P}_{3}=11.04 \mathrm{kips} \\
\mathrm{C}_{\mathrm{C}}=-48.52 \mathrm{kips} & \text { Total load }=22.08 \mathrm{kips} \\
\mathrm{z}=.38 & \\
\mathrm{e}_{\mathrm{S}}=.0059 \mathrm{in} &
\end{array}
$$

Deflection is calculated using the unit rotation diagram

$$
\mathrm{Y}=1.07 \text { inches }
$$

The concrete strain at point four in the post cracking range is taken as $e_{c}=.0025$ in/in.

$$
\begin{array}{rlrl}
\mathrm{a} & =1.885 \text { in } & \mathrm{e}_{\mathrm{s}}=.0081 \\
\mathrm{~T}=49.45 \mathrm{kips} & \mathrm{z}=.413 \\
\mathrm{C}_{\mathrm{c}}=-49.45 \mathrm{kips} & \mathrm{Y}=1.31 \text { inches } \\
\mathrm{M}_{4}=360 \text { in kips } & \\
\mathrm{P}_{4}=11.25 \mathrm{kips} & \\
\text { Total load }=22.50 \mathrm{kips} &
\end{array}
$$




$\begin{array}{ccc}\begin{array}{c}\text { Strain } \\ e_{c} \text { in/in }\end{array} & \begin{array}{c}\text { Total Load } \\ \text { kips }\end{array} & \begin{array}{c}\text { Deflection } \\ \text { inches }\end{array} \\ .000324 & 11.66 & .061 \\ .0010 & 16.46 & .27 \\ .0015 & 20.34 & .48 \\ .0020 & 22.08 & 1.07 \\ .0025 & 22.50 & 1.31\end{array}$

The values of $e_{c}$ and total load are plotted in Figure $D-4$, and the values of total load and deflection are plotted in Figure D-3. The experimental static load-strain and static load-deflection curves are shown also for comparison. 


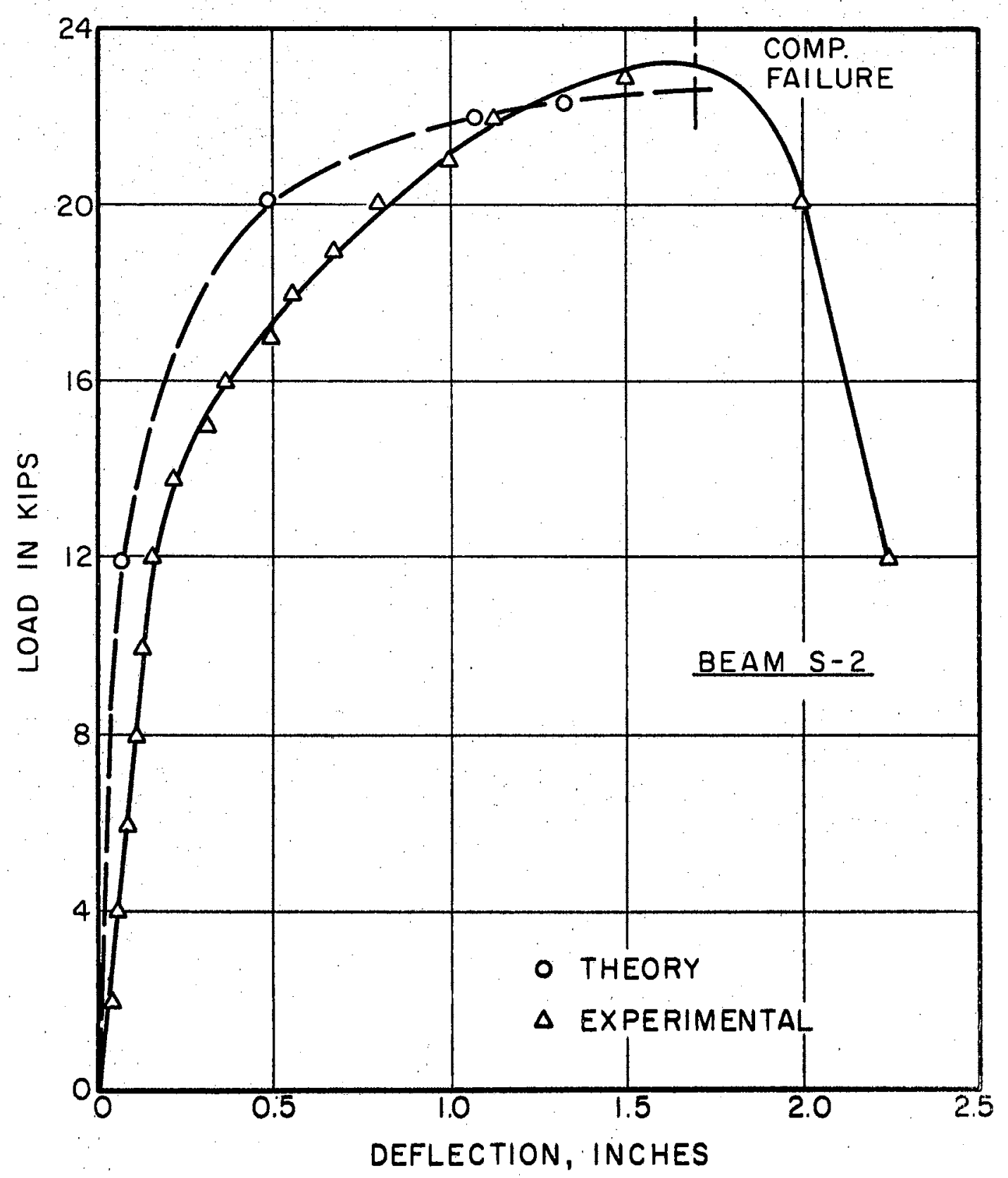

Figure D-3. Load-Deflection Curve Beam S-2 


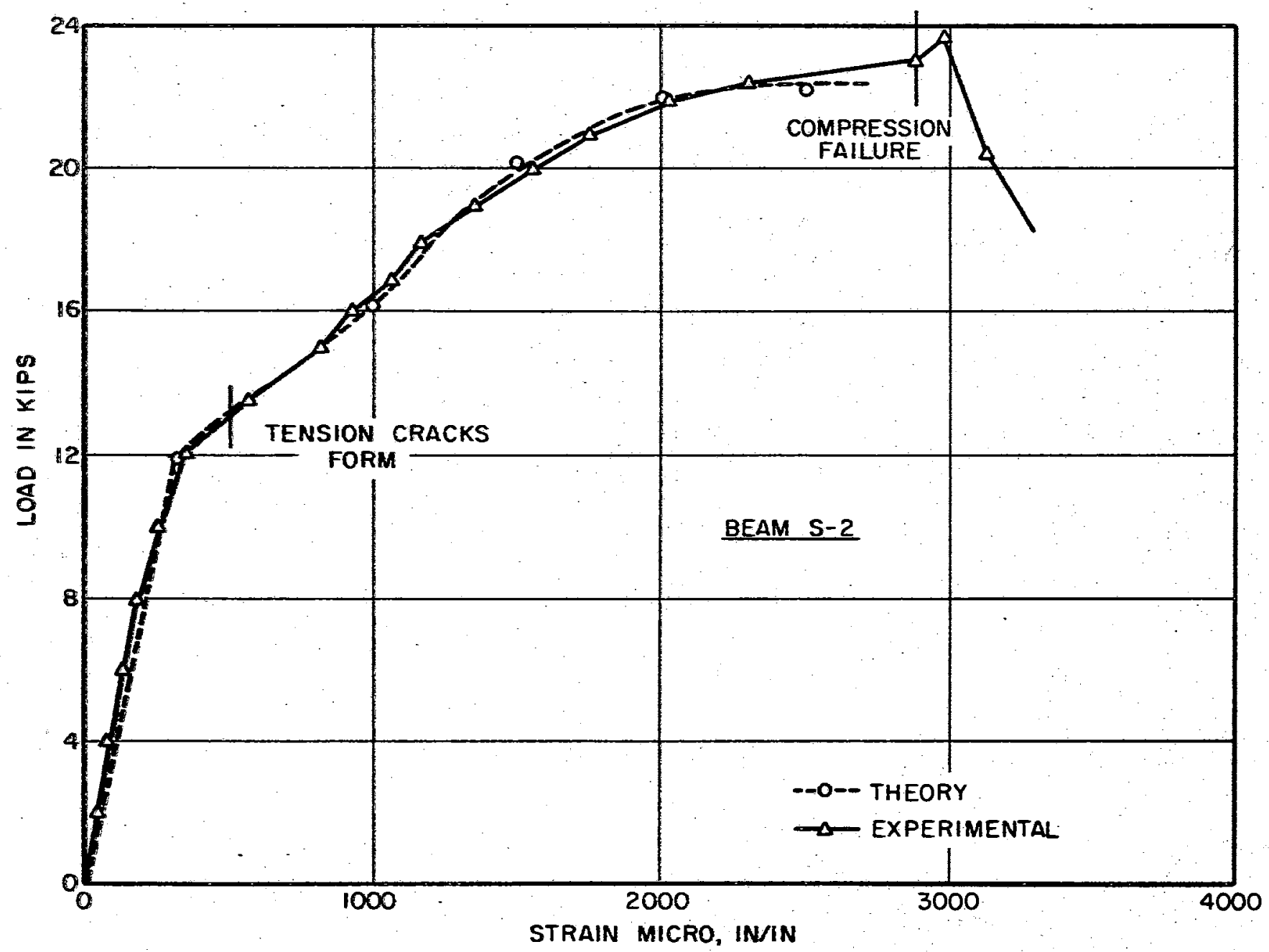

Figure D-4. Load-Strain Curve Beam S-2 
APPENDIX E

DYNAMIC TEST RESPONSE CURVES 

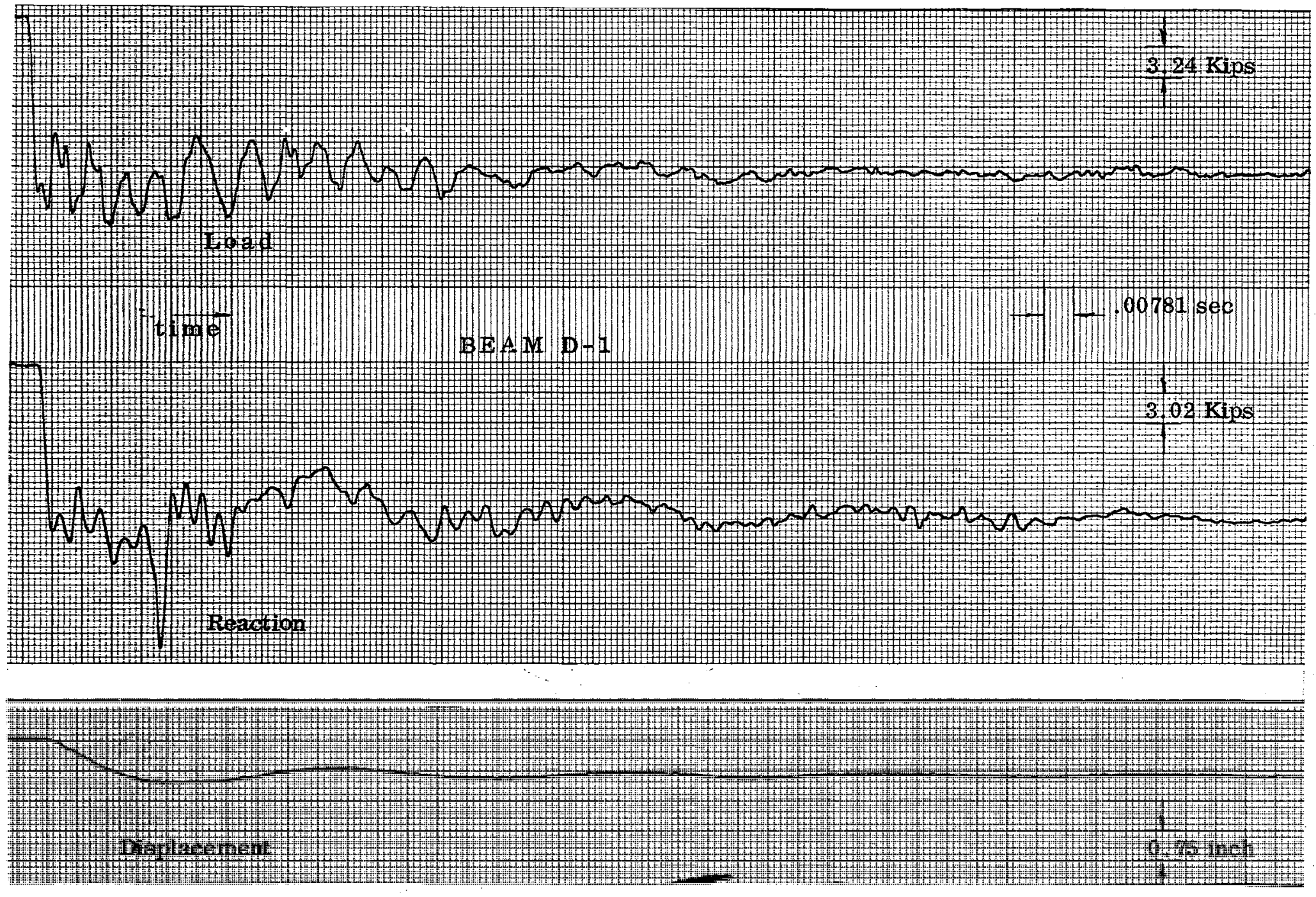

Figure E-1. Dynamic Response Beam D-1 

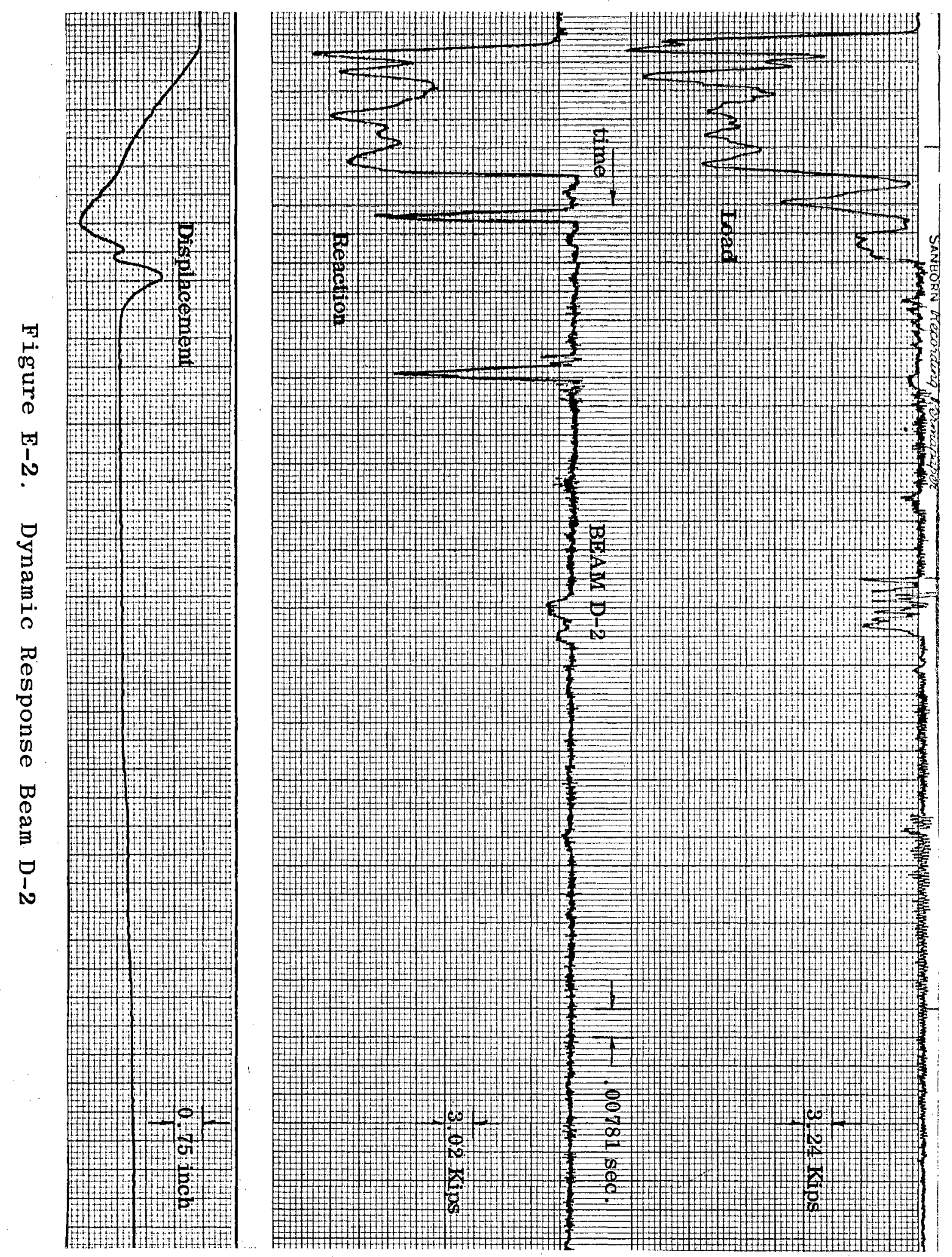









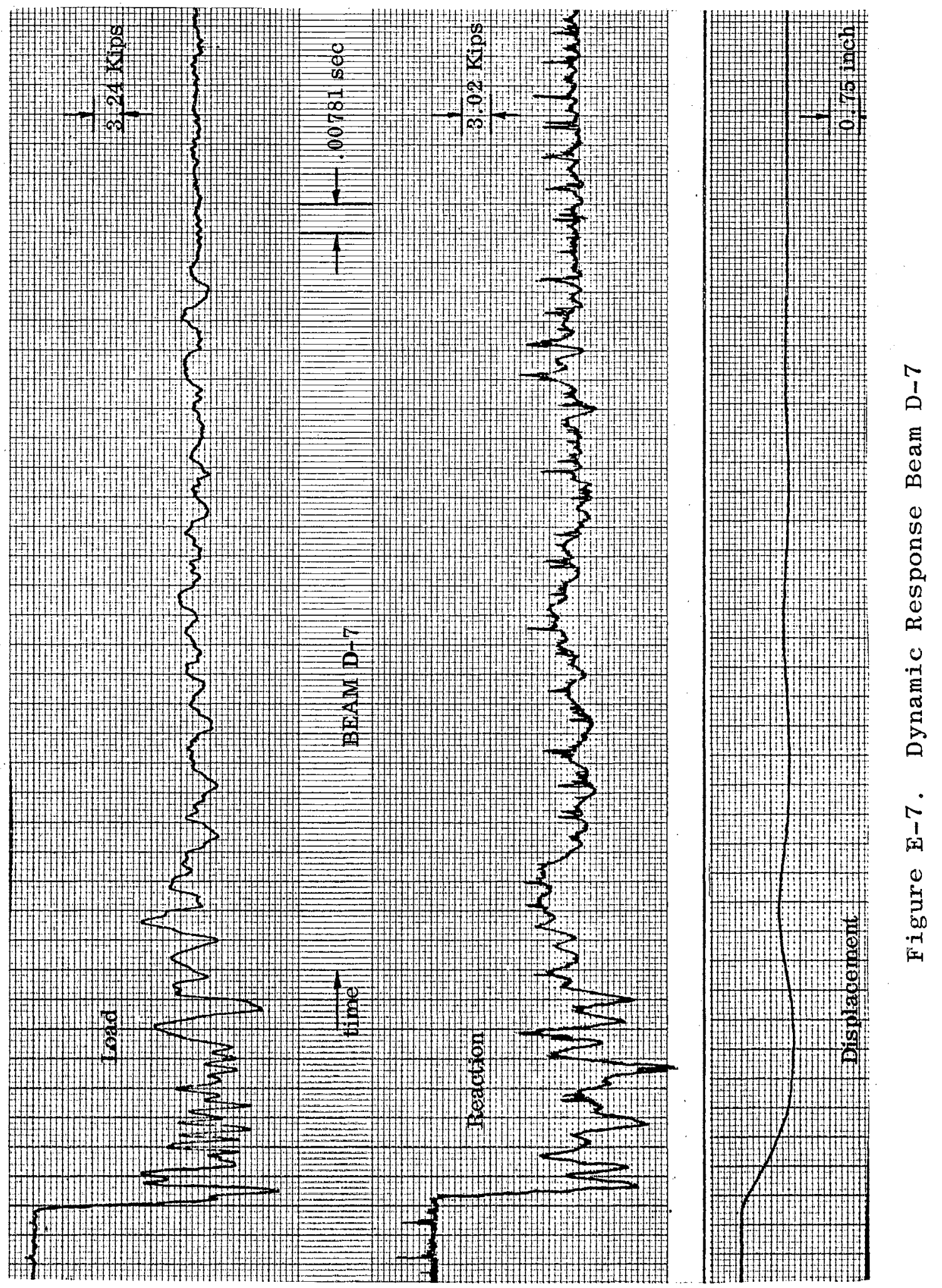




Figure E-8. Buildup and Delay Time Beam D-6 


\section{APPLICATION OF THEORY FOR DYNAMIC LOADS}

The response of a simply supported beam subjected to a cyclical impulsive loading was shown previously as:

$$
\begin{aligned}
Y & =e^{-\varphi_{w_{n}} t}\left(A \cos \sqrt{\varphi^{2}-1} w_{n} t+B^{\prime} \sin \sqrt{\varphi^{2}-1} w_{n} t\right) \\
& +\frac{F_{1}}{k}+\frac{F_{1} e^{-\alpha t}}{m_{e}\left(\phi^{2}+\theta^{2}\right)}[\phi \cos B t+\theta \sin B t]
\end{aligned}
$$

The system is idealized as a single degree of freedom system. As shown in Reference 1 , the effective mass $m_{e}$ is taken as $0.78 \mathrm{~m}$.

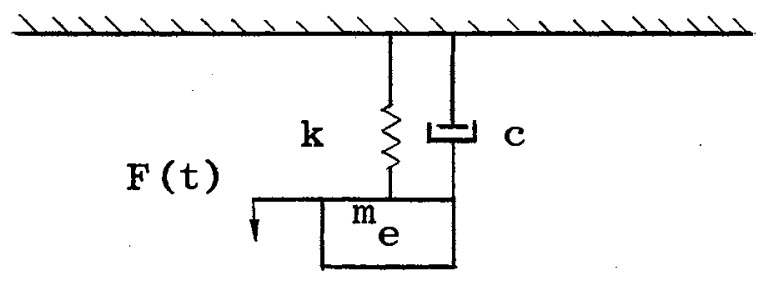

Figure E-9. Equivalent spring Mass System

To apply the theory, Beam D-4 was selected. From Figure E-4 the natural period of the beam was obtained from the deflection curve as:

$$
\mathrm{T}_{\mathrm{n}}=68.9 \mathrm{~m} \mathrm{sec} / \mathrm{cycle}
$$

The logarithmic decrement was also obtained from the deflection curve.

$$
\delta=\ln \frac{x_{n}}{x_{n+1}} \approx \ln 4=1.38
$$


Damping factor: $\}=\frac{\delta}{2 \pi}=.22$

Natural frequency: $w_{n}=\frac{2 \pi}{T_{n}}=91.1 \mathrm{rad} / \mathrm{sec}$.

The spring constant is calculated as:

$$
k=m_{e^{2}} w^{2}=11,1701 b / \text { in }
$$

Critical damping: $\quad c_{c}=w_{n} \times 2 m_{e}=245.24$

Coefficient of damp: $\quad c=\zeta_{c}=54$

The spring constant $k$ may be calculated theoretically by determining the natural period of vibration (26).

$$
\mathrm{T}_{\mathrm{n}}=\frac{2 L^{2}}{\mathrm{n}^{2} \pi} \sqrt{\frac{\mathrm{A \gamma}}{\mathrm{E}_{\mathrm{c}}{ }^{1} \mathrm{~g}}}
$$

where

$$
L=\text { clear span inches }
$$

$$
\mathrm{n}=\text { mode of vibration }
$$

$A=$ cross-sectional area inch $^{2}$

$\gamma=$ weight of material per unit volume $1 \mathrm{~b} / \mathrm{in}^{3}$

$E_{c}=\operatorname{modulus}$ of elasticity $1 \mathrm{~b} / \mathrm{in}^{2}$

$I=$ moment of inertia in 4

$\mathrm{g}$ = acceleration due to gravity

Since the beam cracks almost immediately upon impact of the load, the transformed section was used to compute the area $A$ and the moment of inertia I. At dynamic loads 30 per cent greater than the ultimate static load, the steel has gone into the plastic range. Review of the static load deflection analysis shows that the uncracked 
section has a dimension "a" that varies within limits of 2.2 to 2.0 inches. Using these figures:

$$
\begin{aligned}
& \mathrm{n}=\frac{2.5}{4.5}=.555 \\
& \mathrm{~A}=2.1(8.0)+.555(.178)=16.9 \mathrm{inch}^{2} \\
& \mathrm{I}=\frac{\mathrm{ba}}{3}+\mathrm{n}(\mathrm{d}-\mathrm{a})^{2} \mathrm{~A}_{\mathrm{ss}} \\
& \mathrm{I}=\frac{8(2.1)^{3}}{3}+.555(5.9)^{2} .178=28.14 \mathrm{inch}^{4} \\
& \gamma=\frac{667^{3}}{\mathrm{AL}}=.411 \mathrm{lb/ \textrm {in }} 3 \\
& \mathrm{~T}_{\mathrm{n}}=\frac{2(96)^{2}}{(1)^{2} \pi}=\sqrt{\frac{16.9(.411)}{4.5 \times 10^{6}(28.14) 386}} .0698 \\
& \mathrm{sec} . \\
& \mathrm{W}
\end{aligned}
$$

The experimental values were used in the solution of the differential equation.

Inserting the numerical values into the equation it becomes:

$$
\begin{aligned}
Y & =e^{-20.04 t}(-1.645 \cos 88.8 t-.323 \sin 88.8 t) \\
& +1.624+e^{-49 t}(.021 \cos 785.4 t \\
& +.0081 \sin 785.4 t)
\end{aligned}
$$

Taking increments of .00781 seconds the deflection was plotted on Figure E-10, a reproduction of the displacement curve from Figure E-4. 


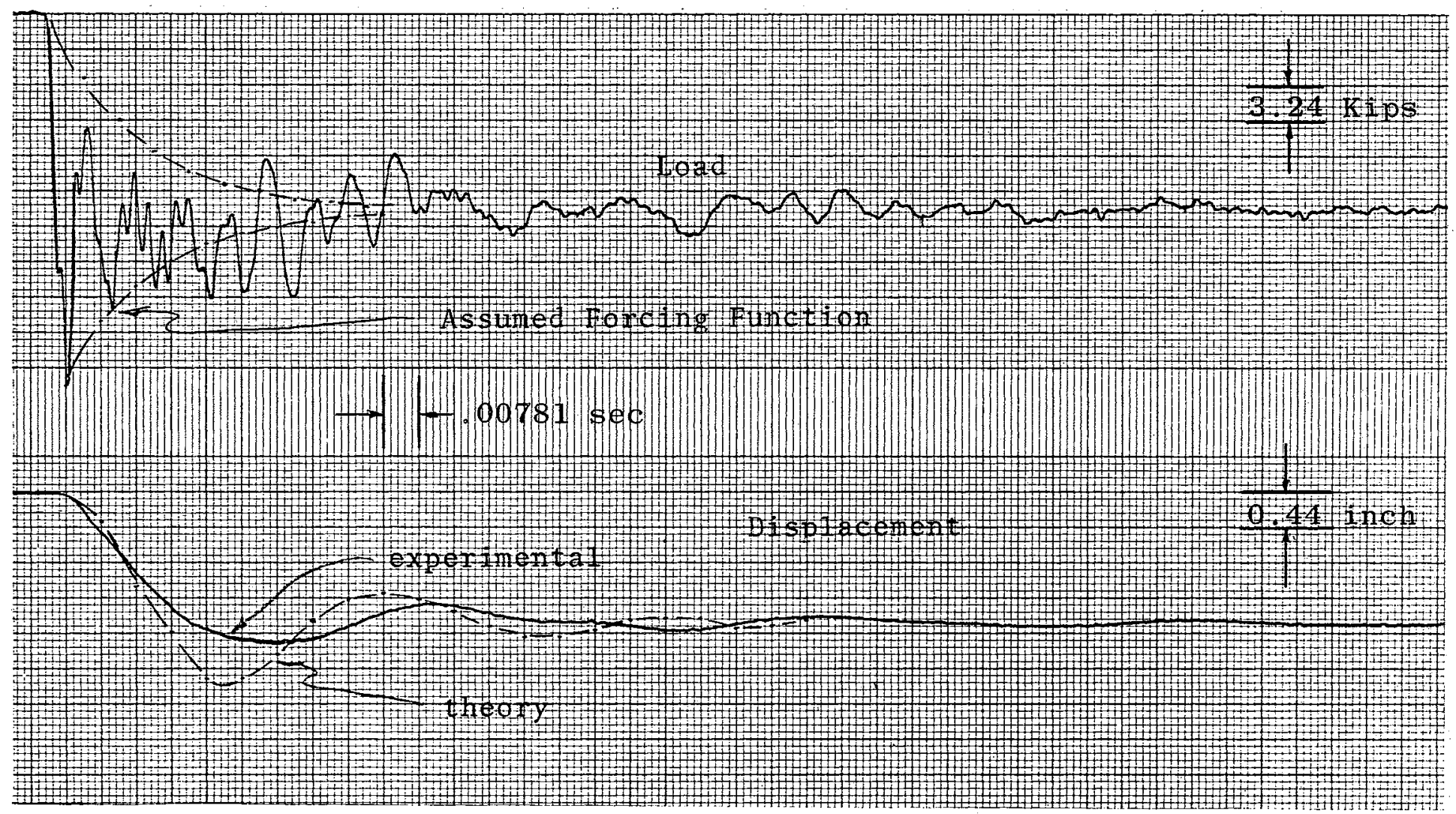

Figure E-10. Theoretical and Experimental Deflection Beam D-4 
VITA

\author{
Wayne A. Hamilton \\ Candidate for the Degree of \\ Doctor of Philosophy
}

Thesis: DYNAMIC RESPONSE OF PRETENSIONED PRESTRESSED CONCRETE BEAMS

Major Field: Engineering

Biographical:

Personal Data: Born January 19, 1932, in Alliance, Ohio, the son of Robert P. and Blanche Hamilton.

Education: Graduated from Randolph High School, Randolph, Ohio in May, 1949. Received the degree of Bachelor of Science in Civil Engineering in June, 1958 from Ohio Northern University, Ada, Ohio. Received the degree of Master of Science in Engineering Mechanics in June, 1960 from Case Institute of Technology, Cleveland, Ohio. Completed requirements for the degree of Doctor of Philosophy at Oklahoma State University in July, 1967 .

Professional Experience: Structural Engineer, Goodyear Aircraft Corporation, Akron, Ohio, summer, 1958. Part time instructor, Case Institute of Technology, Cleveland, Ohio, 1958 to 1960. Field Engineer, A . M. Higley Construction Company, ': Cleveland, Ohio, summer of 1960. University of Maine, Orono, Maine, Civil Engineering Department, Instructor, 1960-1961; Assistant Professor, 19611966; Associate Professor, 1966 to present. Registered Professional Engineer in Ohio and Maine. Member of The American Society of Civil Engineers。 